Article

\title{
Co-Evolution of the University Technology Transfer: Towards a Sustainability-Oriented Industry: Evidence from Italy
}

\author{
Paola M. A. Paniccia * and Silvia Baiocco \\ Department of Management and Law, Tor Vergata University of Rome, 00133 Rome, Italy; \\ silvia.baiocco@uniroma2.it \\ * Correspondence: paniccia@economia.uniroma2.it; Tel.: +39-06-7259-5818
}

Received: 29 October 2018; Accepted: 6 December 2018; Published: 8 December 2018

check for updates

\begin{abstract}
Industry is continuously evolving, reflecting changes in society. An important aspect of this evolution concerns how new digital technologies are used and their effects on innovation and sustainability. Thus, the relationship between university, industry, and government grows stronger, shifting the focus on technology transfer processes from university to industry, at local and national levels. To increase our understanding of how these processes take place, more theoretical and empirical research is required. This paper aims to respond to this call by examining the university technology transfer through a co-evolutionary approach. The study analyses the dynamics of the relationships at different organisational levels within universities able to create sustainability-oriented innovative university spin-offs and start-ups, through the Italian National Innovation Award case. The findings show that the creation of these spin-offs and start-ups are the result of effective multi-level co-evolutionary adaptations within universities, and among university, industry and government. The article contributes to the further understanding of the management of technology transfer by combining some elements from the literature about the co-evolution of social organisations and their environment with some elements from the Triple Helix model of innovation. Moreover, both theoretical and managerial implications emerge, together with suggestions for future research.
\end{abstract}

Keywords: university technology transfer; co-evolution; spin-offs; start-ups; sustainability; case study

\section{Introduction}

Over the last few years, emerging technological breakthroughs—such as artificial intelligence, advanced robotics, the Internet of Things and big data-have triggered the development of the Fourth Industrial Revolution [1], also referred to as "Industry 4.0." Still in its early stages, this new industrial wave is the result of processes that were started years ago and are now deeply affecting firms spanning different industries, transforming their business models, including processes and mechanisms of innovation and governance, structures and roles, system of relations, and firms' boundaries [2-5].

In particular, the term "Industry 4.0" was first mentioned in 2011 at the Hanover trade fair and adopted in 2012 by the German government in the "High-Tech Strategy 2020" action plan in relation to the project aimed at developing advanced technologies in the manufacturing sector [6]. Since then, the term has been associated to a wide range of concepts and to various definitions. However, most academic researchers refer to the integration of emerging digital and virtual technologies into manufacturing that enable "manufacturers to harness entirely digitised, connected, smart, and decentralised value chains" [7] (p. 2) as a key aspect of Industry 4.0. Thus, some main aspects emerge that are relevant for this work and that have implications for the university-industry linkage. Firstly, production systems are highly integrated horizontally and vertically and incorporate customer 
requirements through the real-time data interactions with flexible manufacturing systems as well as the integration of information technology systems into the hierarchy of organisations $[5,6,8]$. Therefore, the relationship between firms and their market results more focused on the users' needs as well as on product personalisation, quality and flexibility, generating new business models. In fact, digital technologies influence decision-making processes, activating multiple evolutionary path of the organisations also of small and medium size (i.e., SME) [4]. Secondly, firms tend to use integrated platforms according to the logic of open innovation that emphasizes organisational factors, such as networks to access information, professional resources, skills and external research results to be exploited in their business models [5]. This implies a higher degree of openness and integration with the external environment and the creation of highly collaborative environments within firms [2]. Thus, stakeholders-and related relationships—change, while at the same time boundaries between firms become increasingly blurred and discontinuities increase [1]. Thirdly, the application of innovations pertaining to Industry 4.0 "has brought, and will continue to bring, profound changes in the global economy on variables such as [...] growth, [and] employment" [5] (p. 2), especially in terms of new skills and competencies [1]. These last, particularly, result increasingly oriented towards data sharing, holistic understanding of demand, and interdisciplinarity [9].

Overall, the issue of sustainability in the context of Industry 4.0 emerges, receiving growing attention from researchers and practitioners. However, this debate is still at an early stage $[7,10]$ where the role of university is yet to be confirmed.

A significant contribution is offered by the holistic vision of sustainability according to the Triple Bottom Line proposed by Elkington [11] especially in relation to the opportunities and challenges in terms of economic, social, and environmental development resulting from digital transformation of industry. According to Elkington [11], sustainability is decomposed into three interdependent dimensions, namely economic prosperity, social justice, and environmental quality, that are able to determine development conditions by interacting with each other. Thus, the realisation of the sustainability objective can be achieved only by jointly taking into account all the three aforementioned dimensions. Industry 4.0 technologies can positively affect the economy, society, and the environment [7] in terms, for example, of firms' productivity and efficiency [4], quality of people's lives [12,13], and environmentally sustainable production and consumption systems [10]. In particular, de Sousa et al. [10] highlight multiple critical factors (e.g., leadership style, organisational culture and practices, flexibility, employees' skills, decisional autonomy, responsibility, cultural and social characteristic of regional and national contexts) able to orient the system of production and consumption towards more environmental sustainability. However, digital transformation can lose its potential to give rise to sustainability-oriented development if not governed and managed jointly considering the requests coming from the above-cited three dimensions according to a holistic view of sustainability. Particularly, various challenges are referred to income inequality, ethical dilemmas, cybersecurity, hacking, existing work activities replacement $[4,13]$. Regarding to this last point, some authors $[13,14]$ highlight that simple tasks will be further replaced, others (e.g., planning, monitoring and decision-making tasks) are likely to automated, and new job profiles are expected to emerge together with new requirements for training and education. However, only few authors have jointly addressed economic, social, and environmental implications of industrial value creation in the context of Industry 4.0 (e.g., [7]). In fact, most academic studies have focused the three dimensions of sustainability separately without considering their mutual relations [5], therefore generating the lack of a holistic view of sustainability, and then, of interlinked phenomena such as digital transformation.

Thus, digital transformation becomes itself a source of relationships and spatial interdependencies (local, national, and multi-national) able to promote sustainability and consequently competitiveness, assigning value to reciprocal relationship between policy makers and decision makers [13]. Therefore, all the actors involved in innovation processes are called to adopt a systemic approach according to a multi-stakeholder and a multi-level (i.e., micro, meso, macro) perspective [15-18]. This means coordinating resources and taking synergic actions on the basis of shared knowledge and core values 
in order to seize the opportunities of the current digital transformation for social responsibility [19-21]. In this regard, the World Economic Forum [22], states:

"An understanding and acceptance of shared human values is critical for a world facing challenges accelerated by increasing complexity and interconnectedness. [ . . ] Technological developments and social change will impact the way people live, work and relate to one another. Companies operating in a sustainable and responsible manner are better placed to succeed in the long term. Moreover, global trade and investment must grow within a framework that encourages good practice both now and in years to come".

Thus, in the context of Industry 4.0 technological development is more dependent on how university, industry, and government (i.e., institutional arrangements), synergistically interact to foster innovation for sustainable growth [23]. Among these innovation actors, the university plays a critical role by generating and transferring the most important raw material—scientific knowledge-for economic and social growth through innovative entrepreneurial activities $[24,25]$. Thus, it follows that the university has a potential role in orienting industry towards sustainability. Moreover, an effective transfer of this scientific knowledge—namely, technology transfer (TT)—from university to industry may be enhanced through government action with a variety of public policies and mechanisms of coordination, regulation and funding [26].

An example of this action is the European Union's 10-year plan to make Europe "the most dynamic and competitive knowledge-based economy in the world capable of sustainable economic growth with more and better jobs and greater social cohesion" [27]. The fact that the expected results has not been reached so far $[28,29]$ highlights that effective interactions among the aforementioned actors are difficult to achieve.

Therefore, the interaction among the abovementioned innovation actors and its potential changes over time play a crucial role in shaping the content and direction of technological development, and have gained substantial interest in the literature since the impact of the Bayh Dole Act (1980) on the research mission of universities and the commercialisation of results. The relevance of these interactions in the commercialisation of research results has led some scholars (e.g., [24]) to propose the Triple Helix model. This model identifies university, industry and government as relatively equal, independent and interacting institutional spheres whose increasing linkages facilitate TT from university to industry. The original model has been progressively developed [30] generating the "Sustainability Twin-Helix model" that balances development and sustainability [31,32]. In this regard, some scholars (i.e., [33]) reinterpret from a systemic perspective the dynamic of the three spheres of innovation identified by the Triple Helix model, highlighting that changes among them result from the interactions with economic, social, and environmental sustainability dimensions, according to the Triple Bottom line.

Thus, a relevant contribution of the Triple Helix model to the analysis of innovation lies in the holistic perspective of the interdependencies and mutual relationships among the spheres-specific actors that generate effective TT processes. However, there are calls to analyse more deeply the single sphere-specific level and "the way they influence the interaction dynamics" [34] (p. 242) by adopting a multi-level analysis [35-39]. It is therefore necessary to holistically capture the dynamic of the interactions within and among the above-mentioned innovation actors-and their variation over time- as well as their effects on different socioeconomic contexts (i.e., regions and countries). This is particularly useful for better understanding the role played by these spheres in relation to the dynamics of industry 4.0. In this regard, it is also important to consider the absorptive capacity [40] of this innovation actors and, consequently, their path dependence [41].

In order to do so, the co-evolutionary approach to the study of the relationships between complex social organisations and their environment (e.g., [42-44]) seems to perfectly achieve this goal. As a matter of fact, co-evolution is a multi-level concept, allowing joint consideration of the dynamics of the interdependencies from the micro to the macro level of a complex social organisation, as well as the interactions, influences, and connections of these organisations with the economic and social 
change [15]. In this vein, an important contribution is offered by the evolutionary economic geography (EEG) literature that focuses on the processes and mechanisms through which the spatial economy transforms itself over time [17]. This perspective implies the analysis of the interactions among different spatial levels (i.e., micro, meso, and macro), highlighting the relevance of local contexts in innovation processes (e.g., [16]). Thus, co-evolution becomes a key concept to explain how to encourage change through synergies within and among university, industry, and government at multiple levels able to stimulate sustainability-oriented innovations, preserving their benefits over time [18].

Positioned in this latest stream of research, the aim of this article is to contribute to filling the identified literature gap by focusing on the single sphere of the university in the context of Industry 4.0 and examining the university TT in promoting sustainable innovation through a co-evolutionary approach, that to the authors' knowledge, is still not adopted in the management studies on this topic. In order to do so, this study combines some of the most consolidated concepts from the management literature about co-evolution with some elements from the Triple Helix model of innovation. In fact, through the adoption of a co-evolutionary approach to examine the overall dynamics of Italian university TT, the article offers a conceptualisation of sustainability-oriented innovative university spin-offs (USOs) and start-ups (USUs) as a result of effective multi-level co-evolutionary adaptations within a university and among university, industry and government.

In particular, the following research questions are posed:

$\mathrm{RQ}(1)$ : Is the evolution of university TT related to the evolution of industry and government?

$\mathrm{RQ}(2)$ : Why and how does the co-evolutionary approach explain the dynamics of university TT?

$\mathrm{RQ}(3)$ : How does university TT can promote sustainability-oriented innovative USOs and USUs?

The article aims to answer these questions by analysing, according to a co-evolutionary approach, the dynamics of the interdependencies and interactions among different organisational levels within the university, focusing on individual and group behaviours, organisational units and processes through the National Innovation Award. This case study is a business plan competition held in Italy at regional and national levels and promoted by the "Italian Association of University Incubators and Local Business Plan Competition" (i.e., PNICube). It is representative of university TT resulting from effective interactions at multiple levels within the university, and aimed at fostering local development through the creation of sustainability-oriented innovative USOs and USUs.

The paper is structured as follows. First, an in-depth description of the evolution of Italian university TT is provided, together with an analysis of the related literature (RQ1). The second part proposes an interpretative framework that helps to identify the relationships among the different levels within universities involved in TT and to capture the main determinants (i.e., mechanisms) of effective reciprocal adaptations among these levels and, consequently, of TT able of creating sustainability-oriented innovative USOs and USUs (RQ2 and RQ3). Substantially, the proposed framework argues that the co-evolutionary approach allows an understanding and explanation of the mutual relationships among different levels within a university, as well as their variations over time related to the influences of internal and external factors. In the third part, findings are gathered through the analysis of the dynamics of the National Innovation Award by adopting the proposed interpretative framework and focusing on individual and group behaviours, organisational units, and processes (RQ3). Finally, discussion, implications, and conclusions, with suggestions for future studies are presented. Overall, the study contributes to the further understanding of the management of the university TT and therefore of its role in the context of Industry 4.0 in promoting sustainability.

\section{The Phenomenon of University TT in Italy: Evolution or Co-Evolution?}

The concept of technology transfer (TT) became popular among academic researchers and policy-makers at the beginning of the 1980s and since then the expression "technology transfer" has been associated with a wide range of uses. For the purposes of this study, the authors opted to use the concept of TT defined by Roessner [45] and widely adopted in the literature (e.g., [46-48]). According 
to Roessner [45], TT is "the movement of know-how, technical knowledge, or technology from one organisational setting to another". Thus, transfer of technology takes place between a source and a recipient—respectively university and industry in this study—resulting in intentional and evolutionary dynamics based on the interactions among individual and group behaviours, organisational structures and processes involved (e.g., $[49,50])$.

Traditionally, a university contributes indirectly to TT through its consolidated missions of education and research aimed at: (i) providing highly qualified personnel to industry also through business ethics courses that can increase students' ability to be morally courageous in organisations [51,52]; (ii) producing and disseminating scientific knowledge through publications and conferences $[53,54]$. However, over the past two decades the strategic role of universities in directly enhancing innovative entrepreneurial activities by exploiting and diffusing scientific knowledge through TT has increased. This has led to the institutionalisation of the third entrepreneurial mission of university able to potentially provide substantial revenues for universities $[55,56]$, and to contribute to socioeconomic development at local and national levels [24]. Particularly, in the context of Industry 4.0, the high growth potential of research-based activities for competitiveness rewards those local and national contexts where research findings can be effectively used by firms to innovate [23]. Thus, the contribution of government to strengthen the links between university and industry by promoting the development of university TT for research-based innovation emerges. Moreover, it is worth noting that in this same context, the need of social and creative skills as well as of inter-discipline in education and research $[1,10]$, also highlights the specific contribution that the first two traditional missions of universities can offer.

The debate around the topic of university TT in Italy comes from authors of different disciplines (e.g., industrial engineering, management, economic sciences) that adopt various approaches and concepts. However, the role played by the university in the context of Industry 4.0 in promoting sustainability is yet to be discovered. Moreover, other aspects are highlighted in relation to the object of this paper.

Firstly, multiple external and internal factors have been identified as able to favour (or limit) university TT development in Italy. These factors range from environmental/institutional (e.g., the dynamics of demand for innovation, technological progress and policies) [57,58], to industrial (e.g., industrial sector life cycle and related dimension, the dynamics of competition) [58], and academic levels (e.g., entrepreneurial attitude, skills and individual characteristics) [59,60]. In particular, the phenomenon emerged in the 1970s and mid 1980s as occasional attempts of pioneer researchers taken without the support of their universities and has intensified since 2000 following some specific national laws on university entrepreneurship, ownership of university patents, and autonomy of single universities [61]. These framework conditions have encouraged universities to design specialised TT organisational units (TTOUs)—such as TT offices (TTOs), incubators and science parks-specifically engaged in TT activities such as patenting, licensing, creation of research-based spin-offs and start-ups [54]. Recently, an institutional arrangement introduced in 2012 by the "Start-up Act" has further strengthened the links between universities and industry [62], generating positive social and economic impacts on local communities [63]. In fact, this is the only framework that regulates innovative start-ups by establishing accurate requirements to determine their innovative character.

According to this law, a new start-up is considered innovative if one of the following three criteria is fulfilled: (i) at least $15 \%$ of company expenses are devoted to R\&D activities; (ii) the total workforce includes PhD fellows and students for one-third of the total staff or, alternatively, Master's graduates for two-thirds; (iii) a registered patent is held, deposited or licensed or, alternatively, a registered software is owned or has been developed internally. In particular, innovative start-ups are eligible for inclusion in a special section of the Business Registry and for specific measure-such as tax credit on incremental research and development costs - that have been included also in the recently launched "Industry 4.0" national plan [63]. 
The number of registered innovative start-ups at the Chamber of Commerce has grown rapidly since 2013 (Table 1), and highlights a survival rate higher than 95\% from 2014 onwards [64]. In fact, most of the exits from the special section of the Business Registry for innovative start-ups are related to the 5-year time limit set by the law for maintaining the status-and related benefits-of innovative start-ups. Moreover, the latest available data (June 2018) show that: (i) a high percentage of these start-ups (19.8\%) has been created by entrepreneurs under 35 while those owned by female entrepreneurs lag behind at $13.6 \%$; (ii) the majority of them $(71.7 \%$ ) provide services to other firms and particularly regarding ICT $(32.9 \%)$, and R\&D (13\%); (iii) $55 \%$ of total innovative start-ups are distributed in northern Italy, $21 \%$ in central Italy, $17 \%$ in the South, and $7 \%$ in the Islands.

Table 1. Italian innovative start-ups.

\begin{tabular}{lcccccc}
\hline & $\begin{array}{c}\text { December } \\
\mathbf{2 0 1 3}\end{array}$ & $\begin{array}{c}\text { December } \\
\mathbf{2 0 1 4}\end{array}$ & $\begin{array}{c}\text { December } \\
\mathbf{2 0 1 5}\end{array}$ & $\begin{array}{c}\text { December } \\
\mathbf{2 0 1 6}\end{array}$ & $\begin{array}{c}\text { June } \\
\mathbf{2 0 1 7}\end{array}$ & $\begin{array}{c}\text { June } \\
\mathbf{2 0 1 8}\end{array}$ \\
\hline $\begin{array}{l}\text { Innovative start-ups registered at the } \\
\text { Chamber of Commerce }\end{array}$ & 1469 & 3128 & 5146 & 6748 & 7398 & 9396 \\
\hline $\begin{array}{l}\text { Entries in the special section of the } \\
\text { Business Registry throughout the year }\end{array}$ & 1479 & 1.735 & 2285 & 2196 & 1519 & n.a. \\
\hline $\begin{array}{l}\text { Exits from the special section of the } \\
\text { Business Registry throughout the year }\end{array}$ & 10 & 76 & 267 & 594 & 869 & n.a. \\
\hline
\end{tabular}

Source: Our elaboration of Italian Ministry of Economic Development data [64,65].

Secondly, it is highlighted that university TT presents different patterns depending on place-specific characteristics (e.g., size of local firms and of economic sectors), and conditions including institutional arrangements [58]. Moreover, the creation of research-based spin-offs and start-ups has raised a growing interest among scholars as important contributors to the development of local economies that positively influence job creation (e.g., [66]). In this respect, in Italy the creation of USOs has grown in intensity and importance since 2000 [64], but is still "immature" as highlighted by Ramaciotti and Rizzo [67] (p. 502) on the basis of a report by the National Agency for the Evaluation of Universities and Research Institutes (ANVUR). In October 2017, the total number of USOs was 1373 , and $72 \%$ of this amount results from spin-offs that have been formed since 2008 (Table 2). This survival rate has to be considered in relation to the mortality rate of newly established firms in their first $2 / 3$ years, which ranges from $32 \%$ to $42 \%$ [68]. Most of these USOs provide services-particularly to innovation (26.4\%) - rather than manufacturing products, and are located in northern Italy $(47.3 \%)$; central and southern Italy host respectively a further $29 \%$ and $23.7 \%$ of USOs.

Table 2. Italian USOs.

\begin{tabular}{ccccccccccc}
\hline & $\mathbf{2 0 0 8}$ & $\mathbf{2 0 0 9}$ & $\mathbf{2 0 1 0}$ & $\mathbf{2 0 1 1}$ & $\mathbf{2 0 1 2}$ & $\mathbf{2 0 1 3}$ & $\mathbf{2 0 1 4}$ & $\mathbf{2 0 1 5}$ & $\mathbf{2 0 1 6}$ & $\mathbf{3 1 . 1 0 . 2 0 1 7}$ \\
\hline USOs at end of December & 457 & 532 & 633 & 734 & 869 & 989 & 1119 & 1246 & 1347 & $1373^{*}$ \\
USOs formed throughout the year & 72 & 75 & 101 & 101 & 135 & 120 & 130 & 127 & 101 & $26^{*}$ \\
\hline
\end{tabular}

* Provisional data. Source: NetVal Surveys [69].

Thirdly, the crucial role played by TTOs in transferring technology through specific organisational services, including business plan competitions, mentoring and business advisory services, is highlighted [69]. In this respect, the "Italian Network of Technology Transfer Offices of Universities and Public Research Organisations" (NetVal), that collects data on university TT in Italy, highlights that almost all universities (96\%) have an internal TTO, and that $55.9 \%$ and $40.7 \%$ of them have an incubator and a science park, respectively. Moreover, some crucial factors that affect their performance are highlighted such as: the availability of financial and human resources as well as of skills and competencies; the degree of integration with departments; the inclusion in the network of relationships with, for example, science parks, business angels, venture capitalists, agencies specialised in TT; and 
the ability of researchers to develop innovative products [70,71]. These factors highlight the existence of contradictions in the interactions within and among all the actors involved in TT.

Fourthly, the existing academic contributions on USOs and USUs do not provide a clear distinction between them. In this respect, Debackere and Veugelers [72] highlight that a limited number of studies compare USOs and USUs analysing their differences in terms of origin and growth patterns. Furthermore, the terms "spin-off" and "start-up" have been variously defined in literature. The term "spin-off" identifies "a new company that arises from a parent organization" [53] (p. 3), namely a university when USOs are considered [73]. However, various and heterogeneous definitions of USOs emerge from the literature that highlight "the status of individuals involved in the new business venturing process [and] the nature of knowledge transferred from university to the new venture" [73] (p. 358). This paper draws on the definition of USOs as "new entrepreneurial activities usually set up by professors, young researchers, PhD students, and generated within academic contexts" [25] (p. 331). This definition is consistent with that adopted by NetVal. Similarly, as various definitions of start-ups can be found in the literature, this study considers a start-up as a new company with a high character of innovation (see for example, [62]) that meets the requirements set by Italian Law and that are adopted also by NetVal and PNICube.

In summary, analysis of the phenomenon highlights that the evolution of university TT is related to the dynamic of the interactions that take place between university, industry and government according to a circular dialectical relationship. This dynamic is necessarily co-evolutionary, i.e., changes to one of these actors cause variations in other actors involved. Moreover, this dynamic is influenced by multiple external (i.e., environmental/institutional or industrial) and internal factors (i.e., academic-specific). Therefore, university, industry and government are interdependent, with mutual influence, and sometimes their reciprocal relationships are contradictory, i.e., dialectic. This implies continuous effective adaptations among different levels within each single innovation actor, and then, unavoidable implications on the effectiveness of university TT and its contribution to sustainable development of economy and society.

Thus, to increase the understanding of university TT in promoting sustainability-oriented innovation (i.e., USOs and USUs) with positive effects on industry and interlinked needs of sustainability, the main problem that arises is how to grasp the influences able to favour (or limit) its positive evolution over time.

It is for this reason that, in the next section, this study proposes a co-evolutionary analysis of university TT, in order to capture the main determinants (i.e., mechanisms) of effective reciprocal adaptations among the different levels within universities involved in TT.

\section{Interpreting University Technology Transfer: Towards a Co-Evolutionary Framework}

The interpretative framework proposed in this section combines some of the most consolidated concepts from the management studies about co-evolution with some elements from the Triple Helix Model. In particular, the framework focuses on the university in order to propose a possible interpretation of sustainable-oriented innovative USUs and USOs as the result of continuous effective co-evolutionary multi-level adaptations.

In a knowledge-based society more and more digitally interconnected [1], TT processes and the start-up of new firms are enhanced by the synergic interactions among multiple innovation actors. Moreover, the importance of knowledge based activities for competitiveness is particularly increasing in the context of the digital transformation [13,42], highlighting the crucial role played by universities in promoting innovation through USOs and USUs, and by government in enhancing university-industry linkage. This linkage requires to be understood in a holistic way and managed dynamically especially in order to promote employment through the development of skills for new jobs [11]. In fact, digital transformation becomes itself a source of relationships and spatial interdependencies (regional, national, and multi-national) able to promote sustainability-oriented innovation to satisfy the real needs emerging from social interconnections, assigning value to local 
socioeconomic contexts and entrepreneurship, and triggering changes in the business models of manufacturing large enterprises and SMEs $[4,13]$.

The Triple Helix of innovation assumes that knowledge-based development is generated by the synergic interactions between three equal and independent institutional spheres (i.e., innovation actors) - university, industry and government—-that while getting closer overlap by taking the role of the other in some regards, i.e., university acting as entrepreneurial agents, industry sharing knowledge, government taking the role of venture capitalist [24]. Thus, each helix experiences ongoing transformations internally because of environmental dynamics, and at the same time is also called to interact with the other two helices in order to find various degrees of mutual adjustment [24]. Over the years, the original model has been enriched [30] in particular with the development of the "Sustainability Twin-Helix model" that balances development and sustainability [31,32].

The concept of sustainability has always been closely connected to the development concept according to the recommendations of the Brundtland report [73]. In this vein, Elkington [11] proposed the Triple Bottom Line to define the sustainability according to a holistic perspective. This view considers, not only the economic dimension, but decomposes sustainability into three interdependent dimensions, namely economic prosperity, social justice, and environmental quality. Thus, all these three dimensions are able to determine development conditions by interacting with each other.

Consequently, full realization of the sustainability objective can be achieved only by jointly taking into account all the three sustainability dimensions. In this regard, some management scholars (i.e., [33]) have integrated the aforementioned Elkington's Triple Bottom line with the Triple Helix model according to a systemic perspective. In this view emerges that the three sustainability dimensions, by interacting with each other, are able to determine changes within and among the three spheres of innovation. Thus, the relevance of multiple factors able to influence the interactions within and among the above-mentioned innovation actors and their potential changes over time emerges clearly. In this regard, it is particularly important to consider the different conditions of specific socioeconomic contexts (i.e., regions and countries), the interlinked absorptive capacity of innovation actors [40], and consequently their path dependence [41].

However, only a few studies on sustainability in the context of Industry 4.0 have taken into account all three sustainability dimensions [7]. Most academic studies have addressed the three dimensions of sustainability separately without considering their mutual relations [5], therefore generating the lack of a holistic view of sustainability, and then, of interlinked phenomena such as digital transformation where the role of university is yet to be discovered.

Thus, to understand how effective technology transfer from university to industry takes place, it is necessary to holistically capture the influences able to favour (or limit) a synergistic interaction at multiple levels within and among the above-mentioned innovation actors as well as its variations over time.

In order to do so, the co-evolutionary approach seems to perfectly achieve this goal in that it allows joint consideration of the dynamic of the possible interdependencies and interactions between the external and internal factors that at different levels of the organisation can generate effective (or ineffective) practices of university TT.

The co-evolution concept—whose roots lie in Darwinian biological assumptions [74]—has been adopted originally in biology to point out the strength of natural selection in determining reciprocal evolutionary change of interacting species [68]. Over the years, this concept has been considered as one of the key concept of Generalized Darwinism and has been widely used to explain the dynamics of the organisation-environment competitive (or cooperative) relationship. This concept has received constant and broad attention in management studies (e.g., [15,41,43,44,75-79]), showing its effectiveness also in the interpretation of phenomena such as innovation and sustainability (e.g., [16,42,80]).

Recently, the co-evolutionary framework has been adopted in the emerging field of research of the evolutionary economic geography (EEG) literature to better understand the processes and mechanisms through which the spatial economy transforms itself over time [17]. Co-evolutionary concept helps 
EEG to explain dynamic processes at different spatial levels (i.e., micro, meso, and macro) highlighting the relevance of local contexts in co-evolutionary dynamics and their interlinked processes such as innovation (e.g., [16]). Why does a phenomenon generate different results in different local contexts? What mechanisms and processes have allowed these different results? These are key issues that in practical terms can be addressed through the EEG lens.

According to a widely shared definition, co-evolution is "the joint outcome of managerial intentionality, environment, and institutional effects" [76] (p. 526). Thus, co-evolution between an organisation's strategic intentionality and the institutional/environmental pressures [81] allows to reconsider organisational adaptation mechanisms [44]. The central aspect is that neither of these two forces is able, by itself, to define organisational adaptation, but both are necessary. This new view of the organisational adaptation draws on the dialectical assumptions by Benson [82], Hrebiniak and Joyce [83] and Weick [84] for which the adaptation is substantially defined by interdependencies and interactions between organisations' competitive power and environmental pressures that change dynamically over time. Co-evolution implies that organisation's strategic intentionality results from the interactions that take place at different organisational levels of a complex social organisation. Therefore, the organisation is not only an object, but also a subject of evolutionary change [79], and then, all the actors involved are called to adapt effectively, in a proactive search for solutions to common problems [85].

As a matter of fact, co-evolution is multi-level, allowing joint consideration of the dynamics of the interdependencies from the micro to the macro level of a complex social organisation as well as the interactions, influences, and connections of these levels with the economic and social change [68,76]. This means that it takes place not only among different organisations but also within the organisation itself. Consequently, co-evolution can be seen as the joint evolution at multiple levels of organisational practices. This idea of organisational practices is the result of co-evolutionary process, based on the variation selection and retention of useful variants. Thus, the importance of organisational adaptation at multiple levels (micro, meso, macro) within the same organisation emerges, shifting the focus between individual and group behaviours [15,18].

Evidence from the literature on TT allows us to identify individuals, groups, and structures involved in university TT, such as: scientists, technology transfer officers [55], departments [38], technology transfer offices, scientific parks, incubators [55], university governance [60]. In a co-evolutionary view, it is possible to identify three levels of analysis and the dynamics of the interdependences within and among them. Starting from the bottom of the university hierarchy linked to TT, these levels are: (i) the micro level, which refers to university departments where academic research is carried out through the interactions between different actors (e.g., scientists, researchers, $\mathrm{PhD}$ fellows and students, administrative personnel); (ii) the meso level, regarding TTOUs (e.g., TTOs, incubators, scientific parks), promotes TT processes through various services (e.g., business plan competitions) [70] acting as intermediaries between university and industry; (iii) the macro level refers to university governance responsible for the policies at the basis of favourable framework conditions designed to legitimize and foster TT. This co-evolutionary perspective can be used to reinterpret the relationships among the aforementioned levels to better understand how their interdependencies and mutual influences determine changes in the organisational practices, with effects on the organisation's evolution $[76,86]$. In this regard, two relevant aspects emerge. Firstly, the meso level includes key actors (TTOUs) for connecting the micro- with the macro level, and university with the supra-system of economy and society, increasing interdependences and positive externalities in order to realize sustainability-oriented innovations that require effective co-evolutionary adaptations at multiple levels [17,41-43]. This means that co-evolution at multiple levels within a university is influenced by the co-evolutionary dynamics that take place over time between and within industry and government (and vice versa) $[41,87]$. Of course, the creation and development of TTOUs (meso level) depend on the strategic choice of the university governance/macro level (i.e., organisation's strategic intentionality) based on the awareness of the institutional value of its third mission in promoting sustainability especially in relation to digital 
transformation. Thus, the strategic intentionality of university governance is the enabling condition of TT processes, influencing individual and group behaviours at all the abovementioned levels [88]. In fact, starting from this condition it is possible to activate choices and behaviours aimed at stimulating processes of entrepreneurial competencies and skills development at the micro level, also through specialised organisational units (TTOUs). Secondly, the systemic approach is a basic condition for consolidating or renewing skills and competencies $[17,68,89,90]$. Thus, only the university that has a systemic organisation (to be monitored over time) will be able to effectively adapt to environmental changes, generating sustainability-oriented innovative USOs and USUs. These will positively affect the industry sphere and then the sphere of government, generating well-being for the local and national systems and-according to the evolutionary virtuous circle - on the single sphere of university as well.

In accordance with the above and for the purposes of this work, we propose a co-evolutionary framework that interprets the creation of sustainability-oriented innovative USOs and USUs as the result of virtuous co-evolutionary adaptations at multiple levels within a university, and among university, industry and government.

Figure 1 graphically shows the interpretive framework that is proposed and adopted in this work.

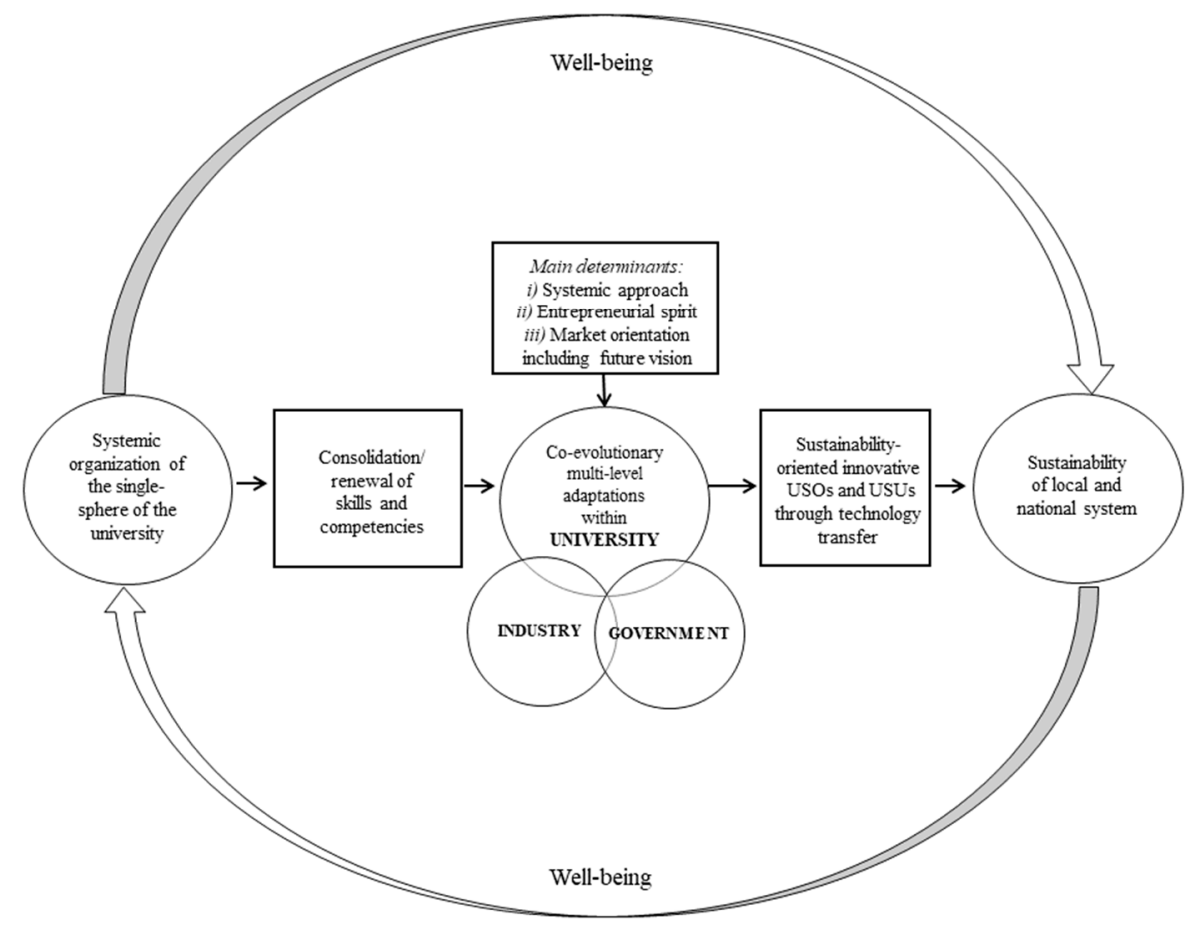

Figure 1. Interpretive framework. Source: Own elaboration.

In their evolution, departments, TTOUs and university governance co-evolve as they are interdependent with mutual influences, and each one supports the others. This interdependence and mutual functionality requires organisational adaptation that develops according to an evolutionary circular relationship with reciprocal feedback mechanisms and a dialectical nature $[79,82,83]$. Thus, the effects of this relationship are largely influenced by the absorptivity capacity and the ability to change of these entities, and then to their path dependence (and related routines). In fact, on the one hand, TTOUs generate pressure through the dynamics linked both to the commercialisation of university research and related revenues for universities, and to the evaluation of third mission activities in relation to the whole university system. On the other hand, university's policies and structures do not always adequately support TTOUs in terms of resources and incentives allocation, and high-quality support services [70,91]. Moreover, departments are not always inclined to support TTOUs because of some issues related to the individuals involved, such as: (i) their lack of entrepreneurial competencies and experience to develop business ideas [38,71,92]; (ii) their temporary commitment 
within departments [71]; (iii) their low propensity to make any changes in the traditional academic career track engaging entrepreneurial behaviour [91,93].

Consequently, in a co-evolutionary view, departments, TTOUs and university governance are called to adapt one to the other over time, renewing themselves, and co-evolving within the wider socioeconomic system of the university.

Substantially, the proposed framework jointly considers-in a holistic view-the possible interdependencies and mutual influences between the external (i.e., environmental/institutional or industrial) and internal factors (i.e., academic-specific) that at different organisational levels of a university could generate appropriate practices of technology transfer. In this framework, the entrepreneurial inclination of a university is the organisational result of interactive dynamics activated by individuals and groups behaviours involved at micro- (departments), meso- (TTOUs) and macro(university governance) levels.

Consequently, as shown in Figure 1, there is an important relationship between systemic organisation and organisational adaptation concepts, from which it is possible to derive three main determinants that this study proposes as mechanisms of effective multi-level co-evolutionary adaptations capable of promoting appropriate practices of TT over time, i.e., able to create sustainability-oriented innovative USOs and USUs, with positive effects for industry. In fact, following a co-evolutionary approach, these determinants of effective organisational adaptation, by activating processes of variation, selection and retention of useful choices, behaviours and interactions, can generate synergies that involved multiple actors within and outside university $[15,18]$.

The determinants are: (i) systemic approach; (ii) entrepreneurial spirit; (iii) market orientation including future vision. Their main contents are discussed below.

Systemic approach refers to the ability to organise and manage in an integrated and dynamic way [89,90] multiple levels [17], fostering inter-organisational transfer of knowledge and capabilities [94], and multi-stakeholder decision making processes [95]. On this basis, it is possible to offer shared solutions to common problems consistent with values emerging from the evolution of the social system, such as sustainability $[12,96,97]$. As such, this is a basic condition to foster competitive interdisciplinary working [39] and strengthen entrepreneurial competencies able to increase the likelihood of sustainability-oriented commercial outputs from academic research projects [33].

Entrepreneurial spirit is conceived as the ability to take risks and the connected responsibilities [51,98] by combining in creative ways the resources and needs of local communities and seizing opportunities from contexts in evolution [99]. This reveals other important skills such as, problem solving, critical thinking, emotional intelligence (e.g., $[38,50,100])$.

Finally, market orientation including future vision refers to the ability to develop market-related knowledge capable of transforming scientific findings into viable products and services in line with emerging technological trends $[4,56,93]$ and with a vision of a sustainable future [7].

In conclusion, within a university a relationship of mutual functionality among departments, TTOUs, and university governance emerges. This relationship is variable over time, necessarily co-evolutionary and sometimes contradictory (i.e., dialectic). This suggests that, to ensure the creation of sustainability-oriented innovative USOs and USUs, effective, ongoing, and co-evolutionary adaptations among multiple actors at different levels are needed within a university and among university, industry and government. In fact, the university is not isolated from the socioeconomic context but it is a co-evolutionary component of this system, and then in a functional relationship with industry and government (at regional and national levels), influencing (positively or not) innovation processes.

\section{Methodology}

In line with the proposed interpretive framework and in order to reach the research aims, this study relies on a longitudinal case study analysis following a qualitative approach and a single-case analysis [101,102]. 
This is a useful method for in-depth research exploration of complex phenomenon in evolution within its real-life context [102] when it is necessary to understand complex causal determinants of changes in the relationships between the actors involved, rather than to make wide generalisations [103]. According to the research suggestions for the methodological fit of Edmondson and McManus [104], this method is particularly suitable for studying organisations according to a co-evolutionary approach (e.g., $[43,44,68,76,77]$. In fact, it allows us to analyse the organisation-environment relationship in its real context, from a holistic perspective, and in compliance with time limits [79]. Moreover, the longitudinal nature of this study enables documenting the development of multi-level interactions over an extended period of time. This is fundamental to understanding those processes $[105,106]$ that take time to produce their effects, and then, to be observed.

The selection of the case—i.e., the "National Innovation Award" (PNI)—was driven by the aim to find a representative case [107] in Italy of university TT that results from the dynamics of the interactions at multiple levels within the sphere of university-and their variation over time-aimed at fostering local development through the creation of USOs and USUs. In fact: (i) it is a business plan competition established in 2003 and promoted by the "Italian Association of University Incubators and Local Business Plan Competition" (PNICube) that involves within a university all the three identified levels; (ii) it represents "the leading competition for innovative business projects coming from academic teams of the Italian universities" [108] (p. 559) in the fields of ICT, life science, industrial technologies, Cleanteach and energy; (iii) it has gone through two temporal phases starting from its inception in 2003 to the 2018 edition (i.e., start-up and development of the PNI); (iv) it is organised at regional and national levels. The unit of analysis are is the individual organization.

To investigate this case, the research has gone through three main steps: firstly, competitions held at regional and national levels were identified; secondly, data were gathered and analysed; thirdly, information was interpreted.

This first step of the research highlights that the competitions held at a regional level-the so-called "Start Cup" — are initiatives jointly promoted and organised by universities, public research organisations, economic and institutional actors of the territories (e.g., firms, banks, venture capitalists, local institutions) where universities are rooted. These competitions are open to scientists, researchers, $\mathrm{PhD}$ fellows and students that belong to those universities that promote and organise the initiative locally, and are organised into three main phases: (1) selection on the part of a panel of experts from academic, industrial, financial, and public sectors of the business ideas submitted to the competition; (2) training and mentoring activities designed to enable the selected contestant teams in writing eligible business plans; (3) business plan pitch and winners selection. The competition held at national level takes place among the finalists of all the regional Start Cups. At both levels (regional and national), a panel of experts from academic, industrial, financial, and public sectors, grant monetary and non-monetary awards to the three most innovative business ideas that have been turned into eligible business plans in one of the above-mentioned four specific sectors.

In order to identify the number of competitions held at regional level, the total number of business ideas submitted at this same level, the number of business plans admitted to the national level of the PNI, and their transformation into USOs and USUs, the following documentation has been taken into consideration: (i) PNICube internal reports from 2010 to 2017 on the regional start cups (i.e., number of start cups held at the regional level; number of business ideas submitted to all the start cups; number of eligible business plans); (ii) NetVal annual data from 2010 to 2017 on the national phase of the PNI (i.e., number of finalists; number of business plans turned into USOs and USUs). On the basis of available data, it was possible to identify regional and national levels of the PNI held from 2010 to 2017 (Table 3), and regional and national levels of the PNI grouped according to the Italian regional contexts from 2014 to September 2017 (Table 4). 
Table 3. Regional and national levels of the PNI (2010-2017).

\begin{tabular}{|c|c|c|c|c|c|c|}
\hline & $\begin{array}{c}\text { No. of } \\
\text { Regional } \\
\text { Start Cups }\end{array}$ & $\begin{array}{l}\text { No. of Business Ideas } \\
\text { Submitted at Regional } \\
\text { Level (Start Cups) }\end{array}$ & $\begin{array}{l}\text { No. of Business Ideas } \\
\text { Turned into Business } \\
\text { Plans (Start Cups) }\end{array}$ & $\begin{array}{l}\text { No. of PNI } \\
\text { National } \\
\text { Finalists }\end{array}$ & $\begin{array}{l}\text { No. of } \\
\text { USOs } \\
\text { Created }\end{array}$ & $\begin{array}{l}\text { No. of } \\
\text { USUs } \\
\text { Created }\end{array}$ \\
\hline 2010 & 14 & 538 & 361 & 59 & 19 & 2 \\
\hline 2011 & 17 & 756 & 361 & 69 & 17 & 4 \\
\hline 2012 & 16 & 850 & 368 & 64 & 25 & 12 \\
\hline 2013 & 15 & 1278 & 528 & 55 & 14 & 20 \\
\hline 2014 & 15 & 1219 & 503 & 58 & 16 & 22 \\
\hline 2015 & 18 & 1193 & 570 & 63 & 13 & 12 \\
\hline 2016 & 16 & 1171 & 511 & 65 & 7 & 19 \\
\hline 2017 & 17 & 1074 & 540 & n.a. & n.a. & n.a. \\
\hline Total & & 8079 & 3742 & 433 & 111 & 91 \\
\hline
\end{tabular}

Source: Our elaboration of data from PNICube and NetVal Surveys [69].

Referring to regional and national levels of the PNI held from 2010 to 2017, a total of 8079 business ideas were submitted at the regional level of the competition and $43 \%$ of them were turned into business plans. Over the same period of time, $12 \%$ of those business plans were selected and admitted to the national phase of the PNI. Overall, a total of 111 USOs and 91 USUs were created within the PNI framework.

Table 4. The PNI in different Italian regional contexts (2014-September 2017).

\begin{tabular}{cccccc}
\hline $\begin{array}{c}\text { Italian Regional } \\
\text { Contexts }\end{array}$ & $\begin{array}{c}\text { No. of Business Ideas } \\
\text { Submitted at Regional } \\
\text { Level (Start Cups) }\end{array}$ & $\begin{array}{c}\text { No. of Business Ideas } \\
\text { Turned into Business } \\
\text { Plans (Start Cups) }\end{array}$ & $\begin{array}{c}\text { PNI } \\
\text { National } \\
\text { Finalists }\end{array}$ & $\begin{array}{c}\text { No. of } \\
\text { USOs } \\
\text { Created }\end{array}$ & $\begin{array}{c}\text { No. of } \\
\text { USUs } \\
\text { Created }\end{array}$ \\
\hline North Italy & 2077 & 992 & 136 & 31 \\
Central Italy & 311 & 174 & 51 & 11 \\
South Italy and Islands & 1197 & 418 & 97 & 0 \\
Total & 3583 & 1584 & 284 & 42 & 22 \\
\hline
\end{tabular}

Source: Our elaboration of data from PNICube and NetVal Surveys [69].

Regarding, regional and national levels of the PNI grouped according to the Italian regional contexts from 2014 to September 2017, regional Start Cups held in northern Italy generated the highest number of PNI national finalists as well as the highest transformation rate of business plans into USOs $(23 \%)$ and USUs $(10 \%)$, followed by central Italy (transformation rate of $22 \%$ into USOs, and $4 \%$ into USUs), southern Italy and the Islands (transformation rate of $6 \%$ into USUs).

Data collection followed Yin [102], and was obtained through: (i) direct examinations of the regional and national phases of the PNI (one of the two authors of this paper held a seat in the Board of Directors of the PNICube and is the Coordinator of the Start Cup held in the Lazio Region; the other author is one of the mentors that guide contestants through the phases of the Start Cup competition held in the Lazio Region); (ii) expert interviews [109] with the Directors of the PNICube Board. Interviews have been structured in two parts, one aimed at collecting general information about the interviewee (e.g., name; academic role; name, dimension and localisation of the interviewee's university), the other on the following main themes:

- university entrepreneurial mission (third mission);

- skills, competencies and values held at multiple levels (department/micro, TTOUs/meso, university governance/macro);

- organisational structure (including routines) and management of TT activities and related

- $\quad$ structures (TTOUs)

- $\quad$ orientation towards sustainability and the future held at different levels by the actors involved;

- relationships with other actors within and outside each level of analysis (department, TTOUs, university governance); 
- problems detected, solutions proposed and synergies in the two temporal phases of the PNI (start-up and development).

Moreover, courtroom questioning and event tracking interview techniques have been adopted [108] in order respectively to emphasize facts and events by avoiding questions that yield inaccurate answers, and to put the informant back in the time frame of the events, and thus, enabling a chronology of those events.

All data collected from the above sources have been analysed focusing on individual and group behaviours, organisational units, interdependences and interactions at different levels within universities in order to identify the synergies achieved and their main determinants. As explained in the proposed framework, these determinants (i.e., mechanisms) of effective organisational adaptation activate processes of variation, selection and retention of useful organisational practices, and can generate synergies that involve multiple actors within and outside university $[15,18]$.

In this respect, in-depth analysis of data, through a cross-interview analysis [110], highlighted four main aspects: (1) the changes, over time, in the relationship among all the actors involved at different levels within universities; (2) their effects on the co-evolution dynamics of organisational practices; (3) the consequences in terms of TT processes; and (4) the corresponding creation of sustainability-oriented innovative USOs and USUs.

In order to strengthen confidence and validity in the accuracy of the findings [111], these results were triangulated with information collected from PNICube web page (e.g., press releases; some proposals dated November 2016 to strengthen industrial policy in order to support the innovation ecosystem and the innovative start-up chain); NetVal web page (surveys; documents on training courses focused on Industry 4.0 and aimed at TTOs professionals and researchers); documents on the phenomenon attributable to the Ministry of Education, Universities and Research and of the Ministry of Economic Development; publications in economic and political newspapers (e.g., Il Sole 24 Ore, Milano Finanza, Il Denaro.it; Il Corriere della Sera), and scientific articles. This various information supports the findings in relation to the dynamics of the interactions that take place among all the levels involved in TT and related skills; the management characteristics and policies supporting the phenomenon; to the growing relevance of the TT within specific contexts (local and national).

\section{Findings}

The case study has been analysed, highlighting the synergies achieved at different and interdependent organisational levels of universities and the main determinants of co-evolutionary adaptations that made them possible, i.e., systemic approach, entrepreneurial spirit, market orientation explained in the proposed theoretical framework. These determinants (i.e., mechanisms of effective organisational adaptation) and their synergic effects are reported according to the two temporal phases of the phenomenon under observation.

\subsection{Phase 1: Start-Up of the PNI}

\subsubsection{Systemic Approach}

Findings show that the PNI-business plan competition was established in 2003 on the basis of a strategic choice of the Association of University Incubators aimed at promoting university entrepreneurship with the support of the Ministry for Productive Activities (currently named Ministry of Economic Development). In this phase, few universities decide to promote and organise their regional business plan competitions. In fact, the first edition of the PNI in 2003 was promoted by universities located in just five Italian regions (i.e., Emilia Romagna, Friuli Venezia Giulia, Lombardy, Piedmont, and Veneto) out of a total of 20 regions. This is not surprising as most Italian universities started defining formal policies as well as devoting human resources to design and develop specialized TTOUs at the same time of the PNI inception. In this respect, this five regional Start Cups are good example of cooperative relationships among universities, local institutions and firms on the basis of 
common interests and values. In fact, on the one hand, the governance of universities involved in this first phase is aware of the role that innovative business ideas based on research results can play to tackle emerging problems faced by local and national firms. On the other hand, those institutions and firms that recognise the importance of exploiting research findings for the competitiveness of local and national contexts take part to the promotion and organisations of these first initiatives.

Thus, the strategic choice to participate to the PNI on the part of universities results influenced by two main factors: the institutionalisation of the third mission of universities (i.e., external factor) and the awareness on the part of universities involved of its role in contributing to socioeconomic development at local and national levels, and then to the interlinked innovation processes (i.e., internal factor). Accordingly, the capacity of the governance of these universities to interpret contexts in evolution emerges as a basic condition to stimulate the dynamic of the interactions among all the other actors involved in the business plan competition (and then in university TT), within the university and among the university and the actors of local and national systems.

However, especially in this first phase, even if university governance recognises the opportunities for integrating the PNI related-activities into its current third mission by jointly organising various activities (e.g., awards, practices connected to the regional Start Cups), interactions within departments and among departments and TTOUs can take place in a climate of scepticism shown by researchers and administrative personnel as well. This shed light on individual/group behaviours and practices that are still not aligned to the aims of the initiative, and then on the lack of proper skills, competencies, and processes of organisational units devoted to TT. These internal factors limit the favourable integration at multiple levels, not only within universities but also among universities and the actors from local and national systems.

\subsubsection{Entrepreneurial Spirit}

Evidence show that professors and researchers are stimulated by the PNI to submit innovative business ideas capable of being transformed into research-based firms. In the first edition of the PNI in 2003, a total of 14 business plans elaborated within the five competitions held at regional level has been admitted to the final phase of the award and afterwards two of them have been turned into USOs. Particularly in this first phase, the entrepreneurial spirit of professors and researchers is mainly encouraged by the commitment of the university governance to transfer technology, ways of doing things deeply rooted in the university's culture, the eventual support of some colleagues rather than new practices. In fact, according to the interviews, this phase is still characterized by routines that limit the valorisation of the interdisciplinary character of university TT. On the one hand, professors and researchers usually lack entrepreneurial skills and competencies that are eventually learned but only gradually; on the other hand, TTOUs are not always capable of building effective network of relationships within the university and with public institutions, banks, investors, and other research organisations that can favour knowledge sharing among all the actors involved as well as support in terms of infrastructures, financial resources and complementary technologies. This results in few practices aimed at the formation of multidisciplinary teams that would help professors and researchers to combine their strong knowledge of technology with the ability to identify market opportunities in relation to the dynamics of demand for innovation and according to the values emerging from the technological development. Moreover, this sheds light on the importance of local contexts. All the five regional Start Cups of this first phase are held in northern Italian regions that are characterised by similar factors-such as institutional environment favourable to innovation; propitious economic and social conditions-that play a crucial role in determining the absorption capacity on the part of local contexts of the university's innovation potential, and thus in stimulating the entrepreneurial spirit of professors and researchers involved in the initiatives. 


\subsubsection{Market Orientation}

Findings show that the PNI stimulate all the organisational levels within universities to better understand the market trends and the new values on which development is based by facilitating the creation of network of relationships at local and national level and defining specific admission requirements. In particular, contestant teams are called to submit their business idea emphasizing some relevant aspects, such as: the originality of the idea, its technological content and related technical feasibility, its potential in terms of sustainability promotion, its market potential and value for investors. Accordingly, the transfer of sustainable technologies with practical application to the market research require new practices that might not be in place in this first phase. Particularly in this first phase, the capacity on the part of the universities to promote entrepreneurship and innovation providing the local community with high technology products and services according to sustainability requirements is mainly influenced by the strategic choice of university governance to link the university third mission to sustainable development.

To sum up these first regional Start Cups can be considered as a good example of how the strategic intentionality of the university governance plays a crucial role in stimulating choices, interactions, behaviours of all individuals and groups involved within universities as well as interactions with external actors on the basis of a common awareness of the value of university TT, shared interests, and values.

Findings clearly show that the effectiveness of this strategic intentionality depends primarily on the ability of university governance to interpret the influences deriving from the interdependencies between academic-specific factors (i.e., resources, skills, competences, values), and external factors (i.e., policies, firms' and community needs). Particularly, the ability to adapt and change of all the actors involved emerges as a key aspect of a synergic interaction able to dynamically define organisational practices in support of innovation processes within a socioeconomic context, which aims to sustainably meet demand for innovation.

\subsection{Phase 2: Development of the PNI}

\subsubsection{Systemic Approach}

Evidence shows that since the PNI inception in 2003, competitions held at regional level have gradually increased from five to a maximum of 18 in 2015 and the total number of business ideas submitted at this level has exceeded 1000 units on a yearly basis since 2013. Moreover, according to latest available data [69], a total number of 700 business plans were admitted to the national level of the PNI from 2003 to 2016, and their transformation rate into USOs is $27 \%$, and into USUs is $13 \%$.

Findings highlight that this trend signals a growth both in quantitative and qualitative terms. In particular, from the qualitative point of view, the awareness of the value of TT on the part of the university governance emerges increased, giving rise to a strengthened of the strategic intentionality. This results in new practices to spur entrepreneurship throughout various departments, including those specialised in basis research, and engage with local and national networks. Particularly, this development phase shows that new activities have been put in place such as the design of graduate courses related to TT and entrepreneurship as well as specific lectures within PhD courses that, however, are still not adequately structured (particularly in terms of faculties and departments involved, and adequate number of hours). Moreover, practices emerged in the first phase are progressively consolidated through to the development of specific skills and competencies of TTOUs' technical and professional staff (e.g., networking skills, problem solving, critical thinking) for effectively connecting individuals and groups at multiple levels within university and with local firms and institutions. This is a good example of joint consideration of the interdependencies at multiple levels within universities and among universities and all the other actors involved. However, notwithstanding these practices, findings show that also in this development phase some limits still emerge in relation, for example, to the ability on the part of TTOUs in coordinating resources 
and activities together with local and national actors or speeding up procedures to set up USOs and USUs. The first problem can be partly solved through the support of the PNI that, over the years, has established many cooperative relationships with national and international institutional bodies, venture capitalists (also corporate), banks, firms that invest according to the open innovation concept. Moreover, also the digital platform recently provided by the PNICube to promote most of the business ideas among investors can contribute to solve this problem. Furthermore, recent institutional arrangements contribute to the resolution of the problems linked to the set-up of USUs. In fact, differently from USOs, those USUs that are qualified for inclusion in the special section of the Business Register, become eligible for multiple incentives, including financial, monetary, and fiscal benefits as well as bureaucratic and legal simplifications.

\subsubsection{Entrepreneurial Spirit}

Over the years, universities involved in the PNI have progressively consolidated practices to support professors and researchers in their entrepreneurial activities, also through their first two traditional missions. Notwithstanding their limits, these new activities are considered by those interviewed as valuable because they allow the involvement in the PNI of PhD fellows and students that are more aware of the entrepreneurial opportunities connected to university TT. As a result of these interactions and connected adaptations, professors and researchers in a traditional academic career track are stimulated (and helped) to present innovative ideas that are more oriented to the market. In this respect, findings show that students participation to the initiative has grown over the years (on average $25 \%$ of contestant teams admitted to the competition held at national level includes students).

However, some specific aspects of scientific business plan development still negatively affect the entrepreneurial spirit of professors and researchers. Particularly, this aspects regard: (i) time and costs caused by scientific experimentation; (ii) competitors analysis including the current state of their scientific projects; (iii) the dynamics that can favour the commercialisation of scientific projects before the end of their laboratory phases, and then limit the creation of research-based firms. The interviews show that university incubation activities could help to solve these problems while they may not be particularly necessary for those projects (e.g., ICT projects related to some apps) that are normally characterised by a short time-to-market.

Moreover, findings confirm - as well as in the start-up phase-a diverse capacity on the part of different regional contexts in terms of absorption capacity of the university's innovation potential, and thus in stimulating the entrepreneurial spirit of professors, researchers, $\mathrm{PhD}$ fellows and student. In this respect, it is worth noting the creation of USOs and USUs is often slowed down by some context factors and conditions, such as availability of financial resources, lack of support infrastructure, bureaucratic procedures that make difficult bring innovation to market.

\subsubsection{Market Orientation}

Evidence show that the dynamic of the interactions activated through the PNI within universities and among universities and all the other actors involved at local and national levels has favoured innovation processes through the formation of sustainability-oriented innovative USOs and USUs. In this respect, over the years the PNI has increased the practices aimed at directing business ideas towards sustainability as well as the emerging trends of Industry 4.0. Evidence of this are: (i) two special awards granted at regional and national levels since 2014 and 2015 respectively to the best business plan in terms of social innovation and equal opportunity for female entrepreneurship (in collaboration with the Italian Department for Equal Opportunities); (ii) criteria recently adopted by most Regional Start Cups to select and award business ideas in relation to their content in terms of digital transformation; (iii) themes that the PNI has defined since 2016 ("Towards Industry 4.0" in 2018, "Connecting to the future" in 2017, and "Shaping the future" in 2016) and related awards. Of course, also specific 
initiatives put in place by universities play a crucial role in this phase, such as those aimed at creating direct links between their third mission and Sustainable Development Goals.

Referring to sustainability, universities involved in the PNI show a growing awareness of the beneficial effects of innovative ideas that devote attention to sustainability issues. In this respect: (i) the total number of business ideas related to the Cleantech and energy sector are rapidly increasing (32\% out of a total of 1074 business ideas submitted at regional levels in 2017; 17\% in 2015); (ii) socially innovative business ideas and female entrepreneur initiatives have been received particular attention both at national and regional levels since 2014 and 2015 respectively. A good example of highly technological research projects that positively affect the economic, environmental and social sustainability dimensions is "SPlastica", the innovative business idea that has won the 2018 edition of Start Cup Lazio and has been admitted to the national phase of the competition. It concerns a technology for the production of bioplastic that currently counts for $1 \%$ out of the total plastic produced in Europe. In particular, the object of this business idea is the production of new $100 \%$ biodegradable plastic materials based on natural polymers made from surpluses of no longer edible milk and potatoes, and characterized by wide applicability, relatively low price and high performance in terms of hardness and thermal stability. Not to mention the growing number of research projects that promote sustainable development by integrating new digital technologies. Examples of this are two business projects turned into innovative USUs—namely, re3Cube and Cubbit-that in 2016 won awards respectively in the ICT and Cleantech and Energy sectors of the PNI. In particular, re3Cube provides an Internet of Things system that, activated by simply connecting it to the electrical socket, daily compacts and sterilizes infected wastes, reducing their volume by $90 \%$, and transforming them into a non-dangerous fuel comparable to urban waste. As such, this system lowers corporate waste management costs as well as those costs borne by the community, and reduces the environmental impact of infected wastes. Also, Cubbit provides a technology based on an application of Internet of Things that allows one to create a peer-to-peer network to spread, store and process data, offering unlimited and free cloud storage. In particular, on the one hand, this technology enables every connected device to contribute to the growth of the network; on the other hand, each user obtains a service that is safer and with higher performance and a more positive environmental impact compared to traditional cloud standards. These are examples that should not be neglected, also in relation to the dynamics of the interactions across sectors in the context of Industry 4.0.

Regarding Industry 4.0, findings highlight that a growing number of business ideas have integrated digital and virtual technologies from the last three years. In this respect, the business project "OCORE" is a patent technology that aims at innovating the traditional boat building sector by making use of a 3D printing and robotic technology for the production of big scale components from the design phase to the semi-finished product. OCORE won the 2017 edition of the PNI, and has been turned into USU in 2018. Particularly, the benefits of this technology are linked to the value created through the digitization of processes that allow: increased simplification and flexibility, reduced costs and lower material inputs, interconnection of distributed and decentralised supply chain networks, faster reaction to demand. This helps to overcome problems of traditional boat building and results in new sustainable materials and products that are highly optimized. In addition, it reduces cost of entry into other sectors (e.g., automotive) that requires prototyping with similar mechanic characteristics highlighting how new technologies can lower barriers between inventors and markets. Thus, overall the adoption of this new technology in the traditional boat manufacturing process has positive effects in terms of economic returns while reducing negative environmental impacts. Another example is "SIXXI", an innovative business idea awarded as the best female entrepreneurship initiative in the 2017 edition of the PNI—that has been turned into an USO (SIXXI Factory). Its aim is to transfer scientific knowledge to the edutainment market by manufacturing construction games on the basis of the combination of new digital technologies with the results of the research project "SIXXI-XX Century Structural Engineering: the Italian contribution". To this end, an industrial and technological research agreement with a firm operating in the production line of 3D printers has 
been made, and some partnership with cultural centres and education institutes started. Particularly, this research-based firm produces a series of 3D scientific construction games of models of "Made in Italy" engineering, architecture and design works that are sold "on demand" or self-produced by end-users through home 3D printers. These construction games pursue relevant social objectives by valuing the Italian heritage, involving kids towards STEAM (Science, Technology, Engineering, Arts and Mathematics) education, and stimulating their manual skills and self-production mechanisms. This is a good example of product-oriented innovation that create values for customers. Moreover, also the production model brings positive social implication in relation to the involvement of highly trained technical and scientific staff, both in the design and production of the games and their demonstration at educational laboratories.

Thus, what emerges is the circular evolutionary relationship between the PNI and the trends of Industry 4.0 and sustainability. In fact, the abovementioned examples of USOs and USUs show how the dynamic integration of research results with new technologies can bring benefits through innovative products and processes not only in terms of increased productivity and efficiency of production processes, but also in relation to the efficient and effective use of resources and materials, and the pursuit of social and cultural goals. In this respect, sustainability-oriented innovative USOs and USUs can be seen as good examples of how is possible to improve the productivity and competitiveness of local and national firms-and then of local and national contexts-through practical applications of digital and virtual technologies. However, this implies the awareness of the existence of a relationship of mutual functionality and interactions not only between the organisational levels of universities, but also among universities, firms, and institutions. This relationship is variable over time, necessarily co-evolutionary and sometimes contradictory. Findings show that even if local firms could benefit from the results of these research-based firms in times of new technological trends, however most of them: (i) are still not completely aware of the implications and opportunities linked to the practical application of the results of these researches because of the lack of a systemic organisation and management of the relationships between firms and their environment (systemic approach); (ii) do not respond promptly to these new trends because of some limitations linked to the availability of properly trained human resources and adequate financial resources that influence negatively the evolution of organisational practices (e.g., practices that do not stimulate teamwork, joint initiatives and sharing of knowledge), and then their responses to market trends (market orientation); (iii) have scarcely ability to grasp the opportunities that can derive from the dynamic of the interdependence between external (i.e., emergent values from new trends, such as sustainability) and internal factors (i.e., resource, skill and competences, management commitment and leadership) and their positive effects on the evolution of their firms, (entrepreneurial spirit). At the same time, also universities face three main issues. The first refers to the need for a clear regulatory framework regarding USOs in respect, for example, to the ownership of intellectual rights, and the degree of participation of universities in their social capital (entrepreneurial spirit). The second is related to the systemic organisation and management of available resources as well as of multiple relationships with the other actors that can support research-based firms (e.g., venture capitalists) and stimulate the improvement of the organisational practices over time (systemic approach). In order to solve these contradictions, institutional actors could play a crucial role in promoting policies aimed at changing the regulatory framework, as well as at enhancing university-industry linkage. Moreover, some association operating at national level (e.g., NetVal, PNICube, Confindustria) could facilitate cooperative relationships among all the actors involved aimed at complementing abilities and sharing resources. The third issue concerns their attention and orientation to core values emerging from social evolution while seizing the opportunities of the current digital transformation and to holistically consider the possible effects of university TT on sustainable development at regional and national levels (market orientation).

To sum up, what emerges in this second phase is the need for a university that, more open towards regional and national contexts, dialogues with industry in order to strengthen opportunities for mutual cooperation. Evidence show that sustainability-oriented innovative USOs and USUs can play a crucial 
role in the context of Industry 4.0. However, these research-based firms are still few in number and characterised by an uncertain future. Thus, to foster their further development, it is necessary to tighter the circular evolutionary relationship at multiple levels within universities and among university, industry, and government. This can generate positive effects on the dynamics of interaction among all the actors involved at local and national level, and then on well-being.

Figure 2 graphically presents an overview of the main findings achieved in the two sequential and intertwined phases of the analysis.

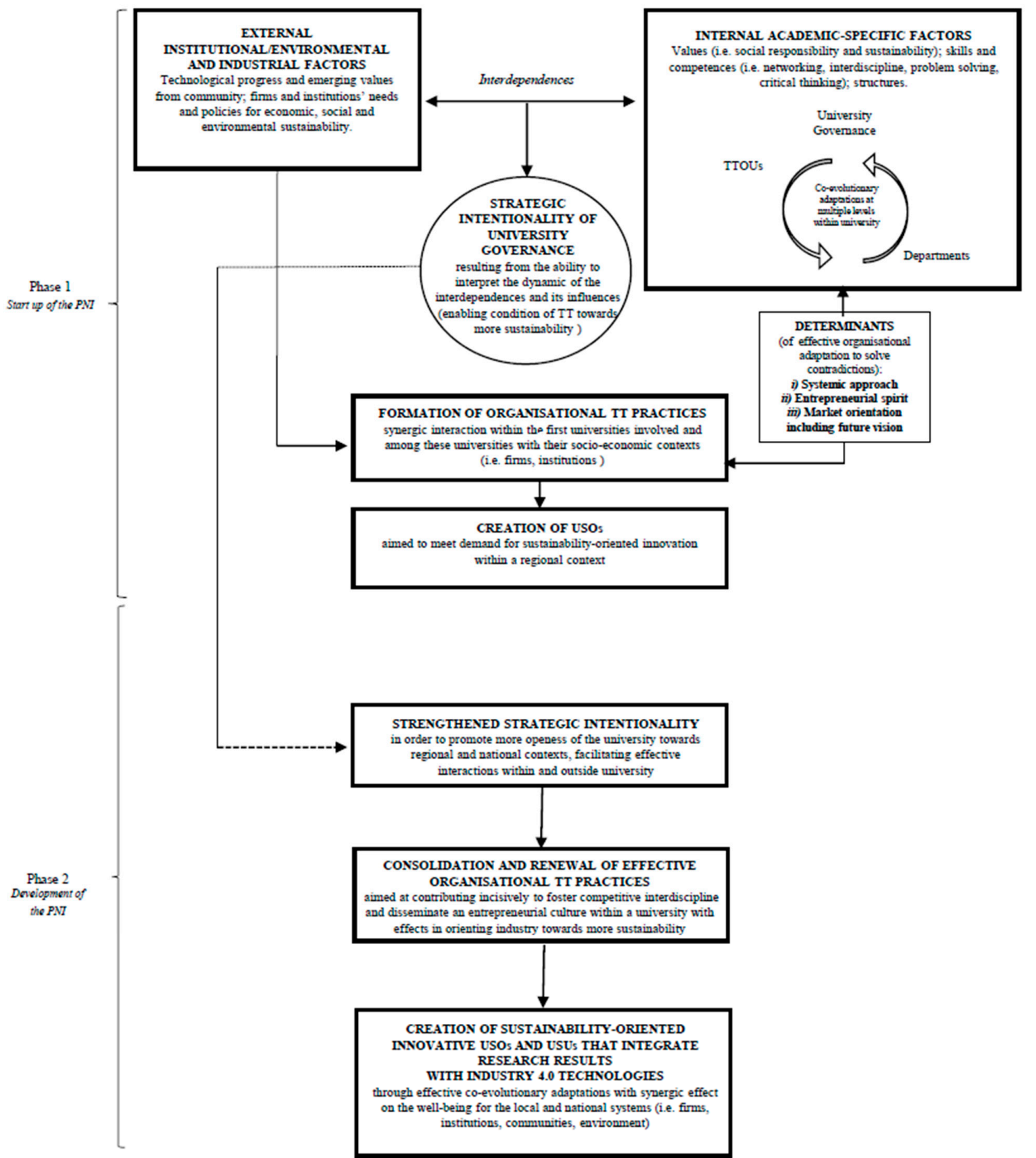

Figure 2. University TT in the context of Industry 4.0: interdependences, and determinants of effective co-evolutionary adaptations. Source: Own elaboration.

\section{Discussion and Implications}

This article has analysed university TT adopting a co-evolutionary approach by presenting a possible interpretation of sustainability-oriented innovative USOs and USUs as result of effective 
co-evolutionary multi-level adaptations. The analysis aims to highlight the dynamic of the interactions at different organisational levels involved in university TT as well as the relationship of mutual functionality between university, industry and government. Thus, it shed light on how the university can contribute to orient industry towards sustainability in respect to the trends of the Industry 4.0.

The analysis has been divided into two sequential and intertwined phases, highlighting the synergies achieved at different and interdependent organisational levels of universities and the main determinants of effective adaptation processes that made them possible. In particular, the study has focused on the dynamic of the interdependencies, mutual influences and interactions at different organisational levels of universities involved in TT. Substantially, the results can contribute to better understand how and what changes in the mutual relationships within university and among all the actors involved at regional e national levels (i.e., university, firms, institutions) have influenced the evolutionary dynamic of university TT with effects on industry.

The results of the case study are consistent with the proposed co-evolutionary framework and confirm that the creation of sustainability-oriented innovative USOs and USUs (i.e., effective university TT) may be possible through virtuous co-evolutionary adaptations based on three main determinants: systemic approach, entrepreneurial spirit and market orientation including a future vision. Following a co-evolutionary approach, these determinants (i.e., mechanisms) of effective organisational adaptation activate processes of variation, selection and retention of useful organisational practices, and can generate synergies that involve multiple actors within and outside the university $[15,18]$. Before analysing the managerial implications that derive from these determinants, some specific peculiarities of the results achieved are discussed below.

Firstly, the results highlight a circular evolutionary relationship that involves, not only different organisational levels within universities, but also the relationship between universities, firms, and institutions. In fact, a university does not act in isolation but interacts with industry over time, and government in supporting TT processes at regional and national levels [24]. Moreover, the relationship between universities and firms is variable over time and sometimes characterised by contradictions and discontinuity (i.e., dialectical) $[79,82,83]$ that can—if not properly managed—adversely affect this relationship. On the one side, university TT is influenced by external (e.g., regulatory framework, emergent values from new trends) and internal (e.g., resources, skill and competences, governance intentionality, management commitment and orientation towards cooperative relationships) factors and conditions that can favour (or limit) the sharing of knowledge, values, culture, and beliefs among professors, researchers, entrepreneurs, and policy makers. On the other side, industry (i.e., local manufacturing firms) are not always able to recognize the value of practical application of scientific knowledge generated and transferred by universities. This for three main reasons: (i) scarce awareness of some new opportunities emerging from contexts in evolution; (ii) availability of human resources with adequate skills and competencies as well as of financial resources whose scarcity is often linked to the small size of these firms; (iii) strategic intentionality of firms and related ability to grasp the interdependence between external and internal factors that influence the evolution of firms. Thus, the relevance of mutual adaptations between university and industry and the critical role played by local and national institutions in enhancing the university-industry linkage emerges. Secondly, the results show that the creation of sustainability-oriented innovative USOs and USUs can contribute to the sustainable development of local and national firms, and then of the contexts in which they are rooted, by integrating research results with Industry 4.0 technologies also in relation to the dynamics of the interactions across sectors in the context of digital transformation. However, sustainability-oriented innovative USOs and USUs are still few in number and characterised by tacit potential with an uncertain future. Thus, to foster the further development of university TT, it is necessary to adapt in proactive way at multiple levels within universities and among university, industry, and government with reciprocal feedback. This can generate positive effects on the dynamics of interaction among all the actors involved at local and national level, and then on well-being. Thirdly, the results show a strong influence of the strategic intentionality of the university governance that acts as 
the linking pin between the external (i.e., environmental/institutional or industrial) and internal (i.e., academic-specific) factors able to influence university TT [15]. Thus, the strategic intentionality emerges as enabling condition of the creation of sustainability-oriented innovative USOs and USUs. It acts through choices and behaviours that stimulate individuals, groups, and practices of TT involving multiple organisational levels within universities [88], and influencing the relationship with institutions and firms. Regarding all the individuals and groups of universities involved in TT (e.g., [38,55,60]), three interdependent levels of analysis emerge in this study, i.e., micro/departments, meso/TTOUs, and macro/governance. In particular: (i) university departments where individual and/or group behaviours are based on personal characteristics and organisational practices (in evolution) that, by interacting, stimulate a growing involvement in TT; (ii) TTOUs, that through multiple interactions between individuals and groups, play a critical role in connecting the micro with the macro level and university with the supra-system of economy and society, in order to increase interdependences and positive externalities, especially in terms of contribution on sustainability and innovation; (iii) university governance that, through its strategic intentionality and on the basis of the awareness of the institutional value of its third mission, supports policies in favour of the development of TT practices as well as behaviours that enable individual and group activities (e.g., to promote entrepreneurial spirit, to invest in organisational structures, to adapt methods of resource allocation, to favour the university participation in interorganisational networks). Therefore, the evolutionary dynamic of university TT results from changes that take place on one organisational level (i.e., macro, meso, or micro) and causes variations in the other two levels.

Overall finding show that to ensure the creation of sustainability-oriented innovative USOs and USUs able to integrate research results with Industry 4.0 technologies, effective, ongoing, and co-evolutionary adaptations among multiple actors at different levels are needed within a university and among university, industry and government. Thus, the enhancement of the university-industry linkage is made possible only if these two entities take into account the three identified main determinants of effective reciprocal organisational adaptations. In fact, the university is a co-evolutionary component of the socioeconomic context, and then in a functional relationship with industry and government (at regional and national levels), influencing (positively or not) innovation processes in the context of Industry 4.0.

\section{Theoretical and Managerial Implications}

The results achieved in this study, although they are not to be generalised and could be improved, are interesting from a theoretical point of view as well as for policy and decision makers, particularly in the context of Industry 4.0.

Regarding theoretical implications, the study offers a co-evolutionary analysis of university TT that conceptualises the creation of sustainability-oriented innovative USOs and USUs as a result of effective multi-level [35-39] co-evolutionary adaptations, contributing to the further understanding of the phenomenon. In particular, the study combines the management literature about co-evolution (e.g., $[14,41,43,44,68,76-79])$ with some elements from the Triple Helix Model (e.g., [24,34]) adding new elements for opening up new research avenues in the management literature about TT and its connected phenomenon such as digital transformation and sustainability. In fact, this approach-that to the authors' knowledge, is still not adopted in the management studies on this topic-allows us to consider contemporaneously the possible interdependencies between the external and internal factors (at the micro, meso and macro levels) able to influence the university TT and, therefore, to identify the main determinants of effective organisational adaptations within the single sphere of the university and between universities, industry and government. This implies mutually effective adaptations of organisational practices within universities over time.

This study confirms that effective university TT can contribute incisively to foster competitive interdisciplinary working [39] and disseminate an entrepreneurial culture within a university with effects in orienting industry towards more sustainability. This effectiveness implies virtuous multi-level 
co-evolutionary adaptations within the single sphere of university, and then, among this sphere and local and national innovation actors, namely industry and government [24,47].

The managerial implications are discussed below taking into account the three identified determinants of effective co-evolutionary adaptations at multiple levels within universities and among universities and all the other actors involved. Therefore, these implications concern the university as well as its effective reciprocal adaptation with industry. Firstly, the need to grasp the opportunities for integrating Industry 4.0 technologies and research results to orient industry towards sustainability that implies effective multi-level organisational adaptation. Thus, it is necessary to organise and manage in an integrated and dynamic way multiple relationships of mutual functionality at different interdependent levels (i.e., macro, meso, micro) within and outside universities, as a prerequisite for fostering interorganisational transfer of knowledge and capabilities with positive effects in terms of regional socioeconomic growth and competitiveness (systemic approach). Secondly, the need to understand and manage competitive interdisciplinary working in order to favour the appropriate integration of Industry 4.0 technologies and research results, and then the creation of USOs and USUs oriented towards sustainability; i.e., combining resources and needs of local communities. This requires the development of appropriate skills and competencies as well as the renewal of organisational practices with responsibility and creativity (entrepreneurial spirit). Thirdly, the need to select Industry 4.0 technologies that are coherent with core values emerging from social evolution in order to develop market-related knowledge capable of transforming scientific findings into products and services more focused on the users' needs as well as on product personalization (market orientation including future vision).

These managerial implications require to be carefully considered by governance of the university sphere as well as by entrepreneur of industry- and policy makers of the government- spheres to define dynamically priorities, orient strategies, allocate resources, as well as resolve contradictions with beneficial effects for sustainable development in the context of Industry 4.0.

\section{Conclusions}

This article is an attempt to understand the contribute of the university with respect to the trends of Industry 4.0 by proposing a co-evolutionary analysis of the technology transfer from the university to industry and analysing the case of the National Innovation Award. To date, the role played by the university in respect to these trends is still neglected while there are calls to analyse more deeply the single innovation actors (i.e., university, industry and government) and "the way they influence the interaction dynamics" with effects on innovation also through effective TT processes [34] (p. 242) by adopting a multi-level analysis [35-39]. This article argues that a better understanding of the overall dynamics of the university TT can shed light on the relationship of mutual functionality between university and industry and on how this relationship can promote sustainable development by combining research results with Industry 4.0 technologies. The issue of sustainability in the context of Industry 4.0 is receiving increasing attention from researchers and practitioners. However, only a few studies on sustainability in these context have taken into account all three sustainability dimensions [8]. Most academic studies have addressed the three dimensions of sustainability separately without considering their relationships [5], therefore generating the lack of a holistic view of sustainability, and then, of interlinked phenomena such as the exploitation of digital technologies. However, the synergic interaction between university and industry depends not only on their capacity of reciprocal effective adaptation over time, but also on the ability that each of these spheres has to adapt proactively to social and environmental developments in which digital transformation plays a critical role. The analysis attempts to shed light on the dynamic of the relationship of mutual functionality between university and industry, and thus on how the university can contribute to orient the industry towards sustainability in respect to the trends of the Industry 4.0. 
The main limitations of this study are twofold. Firstly, it analyses a business plan competition that-even if the leading one in Italy-is one of the possible instruments to promote university TT. Secondly, the research is focused on a specific national socioeconomic system.

Consequently, future investigations may be extended to: (i) other activities able to promote TT at regional and national levels; (ii) other specific socioeconomic systems at an international level by assessing possible evolutions and comparing their positive effects in those contexts.

Finally, future researches could validate the three identified main determinants capable of promoting virtuous co-evolutionary adaptations at multiple levels within the other two spheres of innovation (i.e., industry and government), even to the further understanding of the evolutionary circular relationship among them, and then on innovation processes in the context of Industry 4.0. In this respect, a promising and relevant area of extension of the investigation regards social responsibility as a constitutive component of the systemic approach by taking into account possible behaviours guided by diverging interests in respect to the purposes of university TT. In addition, in order to evaluate deeper the impact that sustainability-oriented innovative USOs and USUs have on industry, a further development of this investigation will have the opportunity to be supported by statistical and quantitative analysis tools (e.g., historical data on performance of USOs and USUs' created in different economic sectors and localised in the different regional contexts) as well as further qualitative evidence-based case studies (e.g., academic team interviews). Furthermore, future researches could contribute to develop a detailed understanding of the distinction between USOs and USUs.

Author Contributions: This paper is the result of a common research by the authors. Both of the authors conceived the paper's research questions and aim, and contributed substantially to its development. In particular, P.M.A.P. focused on the theoretical framework and on the Discussion and Implications section ( $§ 3$ and $\S 6)$. S.B. concentrated on the phenomenon of university technology transfer in Italy and on the Methodology and Findings sections $(\S 2, \S 4, \S 5)$. The Introduction and Conclusions sections ( $\$ 1$ and $\S 7)$ are common to the authors. the various sections.

Funding: This research received no external funding.

Acknowledgments: The authors acknowledge PNICube for data on the National Innovation Award case study.

Conflicts of Interest: The authors declare no conflict of interest.

\section{References}

1. Schwab, K. The Fourth Industrial Revolution; World Economic Forum: Geneva, Switzerland, 2016; ISBN 9781944835002.

2. Baldwin, C.Y.; Clark, K.B. Design Rules: The Power of Modularity; MIT Press: Cambridge, MA, USA, 2000; Volume 1, pp. 1-451.

3. Schmidt, R.; Möhring, M.; Härting, R.C.; Reichstein, C.; Neumaier, P.; Jozinović, P. Industry 4.0-potentials for creating smart products: Empirical research results. In International Conference on Business Information Systems; Springer: Cham, Switzerland, 2015; pp. 16-27.

4. Müller, J.M.; Buliga, O.; Voigt, K.I. Fortune favors the prepared: How SMEs approach business model innovations in Industry 4.0. Technol. Forecast. Soc. 2018, 132, 2-17. [CrossRef]

5. Piccarozzi, M.; Aquilani, B.; Gatti, C. Industry 4.0 in Management Studies: A Systematic Literature Review. Sustainability 2018, 10, 3821. [CrossRef]

6. Liao, Y.; Deschamps, F.; Loures, E.D.F.R.; Ramos, L.F.P. Past, present and future of Industry 4.0-a systematic literature review and research agenda proposal. Int. J. Prod. Res. 2017, 55, 3609-3629. [CrossRef]

7. Kiel, D.; Müller, J.M.; Arnold, C.; Voigt, K.I. Sustainable industrial value creation: Benefits and challenges of industry 4.0. Int. J. Inn. Manag. 2017, 21, 1740015. [CrossRef]

8. Lasi, H.; Fettke, P.; Kemper, H.G.; Feld, T.; Hoffmann, M. Industry 4.0. Bus. Inform. Syst. Eng. 2014, 6, 239-242. [CrossRef]

9. World Economic Forum (WEF). The 10 Skills You Need to Thrive in the Fourth Industrial Revolution. Available online: https:/ / www.weforum.org/agenda/2016/01/the-10-skills-you-need-to-thrive-in-thefourth-industrial-revolution/ (accessed on 21 October 2018). 
10. de Sousa Jabbour, A.B.L.; Jabbour, C.J.C.; Foropon, C.; Godinho Filho, M. When titans meet-Can industry 4.0 revolutionise the environmentally-sustainable manufacturing wave? The role of critical success factors. Technol. Forecast. Soc. 2018, 132, 18-25. [CrossRef]

11. Elkington, J. Cannibals with Forks: The Triple Bottom Line of 21st Century; New Society Publishers: Gabriola Island, BC, Canada, 1997.

12. Aquilani, B.; Abbate, T. Open Innovation through Customers: Collaborative Web-Based Platforms for Ethically and Socially Responsible New Products Part 2. In Handbook of Research on Consumerism in Business and Marketing: Concepts and Practices; Kaufmann, H.R., Panni, F.A.K., Eds.; IGI Global: Hershey, PA, USA, 2014; pp. 375-412, ISBN 9781466658806.

13. Xu, M.; David, J.M.; Kim, S.H. The Fourth Industrial Revolution: Opportunities and Challenges. Int. J. Fin. Res. 2018, 9, 90. [CrossRef]

14. Müller, J.M.; Kiel, D.; Voigt, K.I. What Drives the Implementation of Industry 4.0? The Role of Opportunities and Challenges in the Context of Sustainability. Sustainability 2018, 10, 247. [CrossRef]

15. Breslin, D. Interpreting futures through the multi-level co-evolution of organizational practices. Futures 2011, 43, 1020-1028. [CrossRef]

16. Paniccia, P.M.A.; Leoni, L. Co-evolution in tourism: The case of Albergo Diffuso. Curr. Issues Tour. 2017, 1-28. [CrossRef]

17. Boschma, R.; Martin, R. The aims and scope of evolutionary economic geography. In The Handbook of Evolutionary Economic Geography; Edward Elgar Publishing Limited: Cheltenham, UK, 2010; pp. 3-39.

18. Volberda, H.W.; Van Den Bosch, F.A.J.; Mihalache, O.R. Advancing management innovation: Synthesizing processes, levels of analysis, and change agents. Organ. Stud. 2014, 35, 1245-1264. [CrossRef]

19. Porter, M.E.; Kramer, M.R. Strategy and society: The link between corporate social responsibility and competitive advantage. Harv. Bus. Rev. 2006, 84, 78-92. [PubMed]

20. Pontifical Council for Justice and Peace. Vocation of the Business Leader. A Reflection. 2014. Available online: https: / www.stthomas.edu/media/catholicstudies/center/ryan/publications / publicationpdfs / vocationofthebusinessleaderpdf/PontificalCouncil_4.pdf (accessed on 27 July 2018).

21. Larrey, P. Connected World; Penguin: London, UK, 2017; pp. 1-320, ISBN 9780241308424.

22. World Economic Forum (WEF). Values and the Fourth Industrial Revolution: Connecting the Dots between Value, Values, Profit and Purpose. 2016. Available online: http://www3.weforum.org/docs/WEF_ Values_and_the_Fourth_Industrial_Revolution_WHITEPAPER.pdfWorldEconomicForum (accessed on 15 July 2018).

23. OECD. Digital and Open Innovation Project. 2018. Available online: https://www.innovationpolicyplatform. org/system/files/imce/OECD_TIPDigitalOpenInnovation_flyer_20June2018.pdf (accessed on 9 November 2018).

24. Etzkowitz, H.; Leydesdorff, L. The dynamics of innovation: From National Systems and "Mode 2" to a Triple Helix of university-industry-government relations. Res. Policy 2000, 29, 109-123. [CrossRef]

25. Chiesa, V.; Piccaluga, A. Exploitation and diffusion of public research: The case of academic spin-off companies in Italy. RED Manag. 2000, 30, 329-340. [CrossRef]

26. OECD. Assessing the Impacts of Knowledge Transfer and Policy. 2017. Available online: https:/ / www.innovationpolicyplatform.org/system/files/imce/Policy\%20Mix\%20Knowledge\%20Transfer_ flyer_31Jan2018.pdf (accessed on 22 April 2018).

27. The Economist. Do Europeans Want a Dynamic Economy? 2010. Available online: https://www.economist. com/blogs/charlemagne/2010/01/do_europeans_want_dynamic_economy (accessed on 28 April 2018).

28. Krcek, J. Assessing the EU's 'Lisbon Strategy': Failures \& Successes. Inq. J. 2013, 5. Available online: http:/ / www.inquiriesjournal.com/a?id=754 (accessed on 27 April 2018).

29. Sinell, A.; Iffländer, V.; Muschner, A. Uncovering transfer-a cross-national comparative analysis. Eur. J. Innov. Manag. 2018, 21, 70-95. [CrossRef]

30. Carayannis, E.G.; Campbell, D.F. Triple Helix, Quadruple Helix and Quintuple Helix and how do knowledge, innovation and the environment relate to each other? A proposed framework for a trans-disciplinary analysis of sustainable development and social ecology. Int. J. Soc. Ecol. Sustain. Dev. 2010, 1, 41-69. [CrossRef]

31. Etzkowitz, H.; Zhou, C. Triple Helix twins: Innovation and sustainability. Sci. Public Policy 2006, 33, 77-83. [CrossRef] 
32. Etzkowitz, H.; Zhou, C. The Triple Helix: University-Industry-Government Innovation and Entrepreneurship, 2nd ed.; Routledge: London, UK, 2017; pp. 1-342, ISBN 9781317216186.

33. Barile, S.; Saviano, M.; Iandolo, F.; Caputo, F. La dinamica della sostenibilità tra vortici e correnti: Un modello a Tripla Elica. In Sviluppo, Sostenibilità e Competitività Delle Aziende. Il Contributo Degli Economisti Aziendali; Borgonovi, E., Aiello, G., Fellegara, A.M., Eds.; IL Mulino: Bologna, Italy, 2017; pp. 77-98, ISBN 9788815271747.

34. Etzkowitz, H.; Ranga, M. Triple Helix systems: An analytical framework for innovation policy and practice in the Knowledge Society. In Entrepreneurship and Knowledge Exchange, 1st ed.; Mitra, J., Edmondson, J., Eds.; Routledge: New York, NY, USA, 2015; pp. 117-158, ISBN 978-0415750387.

35. Mustar, P.; Renault, M.; Colombo, M.G.; Piva, E.; Fontes, M.; Lockett, A.; Moray, N. Conceptualising the heterogeneity of research-based spin-offs: A multi-dimensional taxonomy. Res. Policy 2006, 35, 289-308. [CrossRef]

36. Rothaermel, F.T.; Agung, S.D.; Jiang, L. University entrepreneurship: A taxonomy of the literature. Ind. Corp. Chang. 2007, 16, 691-791. [CrossRef]

37. Rasmussen, E.; Borch, O.J. University capabilities in facilitating entrepreneurship: A longitudinal study of spin-off ventures at mid-range universities. Res. Policy 2010, 39, 602-612. [CrossRef]

38. Rasmussen, E.; Mosey, S.; Wright, M. The influence of university departments on the evolution of entrepreneurial competencies in spin-off ventures. Res. Policy 2014, 43, 92-106. [CrossRef]

39. Paniccia, P.M.A.; Baiocco, S.; Scafarto, F. TTOs and Successful University Spin-offs: A Co-evolutionary Perspective. In Proceedings of the EurOMA 2018 Book of Abstracts, Budapest, Hungary, 24-26 June 2018; p. 63, ISBN 978-615-5270-43-7.

40. Cohen, W.M.; Levinthal, D.A. Absorptive capacity: A new perspective on learning and innovation. Adm. Sci. Q. 1990, 35, 128-152. [CrossRef]

41. Murmann, J.P. The coevolution of industries and important features of their environments. Organ. Sci. 2013, 24, 58-78. [CrossRef]

42. Murmann, J.P. Knowledge and Competitive Advantage: The Coevolution of Firms, Technology, and National Institutions; Cambridge University Press: Cambridge, UK, 2003.

43. Hodgson, G.M. Understanding organizational evolution: Toward a research agenda using Generalized Darwinism. Organ. Stud. 2013, 34, 973-992. [CrossRef]

44. Abatecola, G. Research in organisational co-evolution. What comes next? Eur. Manag. J. 2014, 32, 434-443. [CrossRef]

45. Roessner, J.D. Technology Transfer. In Science and Technology Policy in the USA Time of Change; Hill, C., Ed.; Longman: London, UK, 2000.

46. Bozeman, B. Technology transfer and public policy: A review of research and theory. Res. Policy 2000, 29, 627-655. [CrossRef]

47. Wahab, S.A.; Rose, R.C.; Osman, S.I.W. Defining the concepts of technology and technology transfer: A literature analysis. Int. Bus. Res. 2012, 5, 61. [CrossRef]

48. Zuniga, P.; Correa, P. Technology Transfer from Public Research Organizations: Concepts, Markets, and Institutional Failures; World Bank: Washington, DC, USA, 2013.

49. Szulanski, G. The process of knowledge transfer: A diachronic analysis of stickiness. Organ. Behav. Hum. Dec. 2000, 82, 9-27. [CrossRef]

50. Paniccia, P.M.A. (Ed.) Knowledge Management Per La Competitività D'impresa; Aracne: Roma, Italy, 2018; pp. 1-371, ISBN 978-88-255-1370-7.

51. Paniccia, P.M.A. La virtù del coraggio nell'imprenditorialità: Dal concetto etico cristiano al concetto imprenditoriale di coraggio. In L'umanesimo Nell'economia Globalizzata; D'Ascenzo, F., Ferri, G., Risso, M., Eds.; Collana Nuovo Umanesimo, Economia, Libreria Editrice Vaticana: Città del Vaticano, Roma, 2015; Volume 12, ISBN 978-88-209-9657-4.

52. Comer, D.R.; Schwartz, M. Highlighting moral courage in the business ethics course. J. Bus. Ethics 2017, 146, 703-723. [CrossRef]

53. Carayannis, E.G.; Rogers, E.M.; Kurihara, K.; Allbritton, M.M. High-technology spin-offs from government R\&D laboratories and research universities. Technovation 1998, 18, 1-11. [CrossRef]

54. Compagno, C.; Pittino, D. (Eds.) Ricerca Scientifica E Nuove Imprese. Spin-Off Accademici e Valore Della Conoscenza; Isedi: Novara, Italy, 2006; pp. 1-384, ISBN 9788880083344. 
55. Phan, P.H.; Siegel, D.S. The effectiveness of university technology transfer. Found. Trends Entrep. 2006, 2, 77-144. [CrossRef]

56. Markman, G.D.; Siegel, D.S.; Wright, M. Research and technology commercialization. J. Manag. Stud. 2008, 45, 1401-1423. [CrossRef]

57. Bosco, G.M. Innovation, R\&D and technology transfer: Policies towards a regional innovation system. The case of Lombardy. Eur. Plan. Stud. 2007, 15, 1085-1111. [CrossRef]

58. Calcagnini, G.; Favaretto, I.; Giombini, G.; Perugini, F.; Rombaldoni, R. The role of universities in the location of innovative start-ups. J. Technol. Transf. 2016, 41, 670-693. [CrossRef]

59. Feola, R.; Vesci, M.; Botti, A.; Parente, R. The Determinants of Entrepreneurial Intention of Young Researchers: Combining the Theory of Planned Behavior with the Triple Helix Model. J. Small Bus. Manag. 2017. [CrossRef]

60. Fini, R.; Fu, K.; Mathisen, M.T.; Rasmussen, E.; Wright, M. Institutional determinants of university spin-off quantity and quality: A longitudinal, multilevel, cross-country study. Small Bus. Econ. 2017, 48, 361-391. [CrossRef]

61. Conti, G.; Granieri, M.; Piccaluga, A. La Gestione Del Trasferimento Tecnologico: Strategie, Modelli E Strumenti; Springer: Milano, Italy, 2012; pp. 1-225, ISBN 9788847019010.

62. Piccarozzi, M. Does Social Innovation Contribute to Sustainability? The Case of Italian Innovative Start-Ups. Sustainability 2017, 9, 2376. [CrossRef]

63. OECD. The Evaluation of the Italian "Start-up Act". 2018. Available online: https://www.oecdilibrary.org / docserver /02ab0eb7-en.pdf?expires=1539848636\&id=id\&accname=guest\&checksum= 1487985C7A06CA2188C2498AC1D141AC (accessed on 22 October 2018).

64. Italian Ministry of Economic Development. Annual Report to Parliament on the Implementation and Impact of Legislation in Support of Innovative Startups and SMEs. 2016-2017. Available online: http:/ / www.sviluppoeconomico.gov.it/images/stories/documenti/Annual_Report_to_Parliament_ Italian_Startup_Act_2017_-_full_text.pdf (accessed on 18 July 2018).

65. Italian Ministry of Economic Development. Secondo Trimestre 2018-Cruscotto di Indicatori Statistici Delle Start-Up Innovative. 2018. Available online: http:/ / www.sviluppoeconomico.gov.it/index.php/it/impresa/ competitivita-e-nuove-imprese/start-up-innovative/relazione-annuale-e-rapporti-periodici (accessed on 18 July 2018).

66. Bolzani, D.; Fini, R.; Grimaldi, R.; Sobrero, M. University spin-offs and their impact: Longitudinal evidence from Italy. Econ. Politica Ind. 2014, 4, 237-263. [CrossRef]

67. Ramaciotti, L.; Rizzo, U. The determinants of academic spin-off creation by Italian universities. RED Manag. 2015, 45, 501-514. [CrossRef]

68. Cafferata, R. Darwinist connections between the systemness of social organizations and their evolution. J. Manag. Gov. 2016, 20, 19-44. [CrossRef]

69. NetVal. Rapporto Netval Sulla Valorizzazione Della Ricerca Pubblica Italiana (2005-2018). Available online: https:/ / netval.it/ (accessed on 24 April 2018).

70. Nosella, A.; Grimaldi, R. University-level mechanisms supporting the creation of new companies: An analysis of Italian academic spin-offs. Technol. Anal. Strateg. 2009, 21, 679-698. [CrossRef]

71. Bigliardi, B.; Galati, F.; Marolla, G.; Verbano, C. Factors affecting technology transfer offices' performance in the Italian food context. Technol. Anal. Strateg. 2015, 27, 361-384. [CrossRef]

72. Debackere, K.; Veugelers, R. The role of academic technology transfer organizations in improving industry science links. Res. Policy 2005, 34, 321-342. [CrossRef]

73. Pirnay, F.; Surlemont, B. Toward a typology of university spin-offs. Small Bus. Econ. 2003, 21, 355-369. [CrossRef]

74. Brundtland, G.H. Our Common Future: Report of the World Commission on Environment and Development; United Nations: New York, NY, USA, 1987. Available online: http:/ / mom.gov.af/Content/ files/Bruntland_Report. pdf (accessed on 20 April 2018).

75. Darwin, R.C. On the Origin of Species by Means of Natural Selection or the Preservation of Favoured Races in the Struggle for Life; John Murray: London, UK, 1859.

76. Lewin, A.Y.; Volberda, H. Prolegomena on Coevolution: A framework for research on strategy and new organizational forms. Organ. Sci. 1999, 10, 519-534. [CrossRef]

77. Ahlstrom, D.; Bruton, G.D. Rapid institutional shifts and the co-evolution of entrepreneurial firms in transition economies. Entrep. Theory Pract. 2010, 34, 531-554. [CrossRef] 
78. Child, J.; Tse, K.; Rodrigues, S.B. The Dynamics of Corporate Co-Evolution; Edward Elgar: Cheltenham, UK, 2013.

79. Cafferata, R. Management in Adattamento: Tra Razionalità Economica, Evoluzione e Imperfezione Dei Sistemi; IL Mulino: Bologna, Italy, 2018; pp. 1-424, ISBN 8815275118.

80. Paniccia, P.M.A.; Leoni, L.; Baiocco, S. Interpreting Sustainability through Co-Evolution: Evidence from Religious Accommodations in Rome. Sustainability 2017, 9, 2301. [CrossRef]

81. Baum, J.A.C.; Singh, J. (Eds.) Evolutionary Dynamics of Organizations; Oxford University Press: New York, NY, USA, 1994.

82. Benson, J.K. Organizations: A Dialectial View. Adm. Sci. Q. 1977, 1, 1-21. [CrossRef]

83. Hrebiniak, L.G.; Joyce, W.F. Organizational Adaptation: Strategic Choice and Environmental Determinism. Adm. Sci. Q. 1985, 3, 336-349. [CrossRef]

84. Weick, K. The Social Psychology of Organizing; Random House: New York, NY, USA, 1969.

85. Lewontin, R.C. Adaptation. Sci. Am. 1989, 239, 157-169. [CrossRef]

86. Argyris, C.; Schön, D.A. Organizational learning: A theory of action perspective. Reis 1997, 77/78, $345-348$. [CrossRef]

87. Grodal, S.; Gotsopoulos, A.; Suarez, F.F. The Co-Evolution of Technologies and Categories during Industry Emergence. Acad. Manag. Rev. 2015, 40, 420-445. [CrossRef]

88. Hambrick, D.C.; Mason, P. Upper echelons: The organization as a reflection of its top managers. Acad. Manag. Rev. 1984, 9, 193-206. [CrossRef]

89. Contingency Views of Organization and Management; Kast, F.E., Rosenzweig, J.E., Eds.; Science Research Associates: Chicago, IL, USA, 1973; pp. 38-56.

90. Golinelli, G.M. Viable Systems Approach (VSA): Governing Business Dynamics; Cedam: Padova, Italy, 2010; pp. 1-396, ISBN 9788813299620.

91. Ambos, T.C.; Mäkelä, K.; Birkinshaw, J.; d'Este, P. When does university research get commercialized? Creating ambidexterity in research institutions. J. Manag. Stud. 2008, 45, 1424-1447. [CrossRef]

92. O'Shea, R.P.; Allen, T.J.; Morse, K.P.; O'Gorman, C.; Roche, F. Delineating the anatomy of an entrepreneurial university: The Massachusetts Institute of Technology experience. RED Manag. 2007, 37, 1-16. [CrossRef]

93. Balderi, C.; Butelli, P.; Conti, G.; Di Minin, A.; Piccaluga, A. Towards an Italian way in the valorisation of results from public research. Impresa Progetto-Electron. J. Manag. 2007, 1, 1-32.

94. Zander, U.; Kogut, B. Knowledge and the speed of the transfer and imitation of organizational capabilities: An empirical test. Organ. Sci. 1995, 6, 76-92. [CrossRef]

95. Freeman, R.E. Stockholders and stakeholders: A new perspective on corporate governance. Calif. Manag. Rev. 1983, 25, 88-106. [CrossRef]

96. Caselli, L. La Vita Buona Nell'economia E Nella Società; Edizioni Lavoro: Roma, Italy, 2012; pp. 1-242, ISBN 978-88-7313-339-1.

97. Siegel, D.S.; Wright, M. Academic entrepreneurship: Time for a rethink? Br. J. Manag. 2015, 26, 582-595. [CrossRef]

98. Gatti, C.; Vagnani, G. Evaluating Corporate Strategic Plans: A Risk-Based Approach. J. Financ. Manag. Anal. 2002, 15, 17-26. ISSN: 0970-4205. first page-last page.

99. Bird, B. Implementing entrepreneurial ideas: The case for intention. Acad. Manag. Rev. 1988, 13, 442-463. [CrossRef]

100. Poggesi, S.; Mari, M.; De Vita, L. What's new in female entrepreneurship research? Answers from the literature. Int. Entrep. Manag. J. 2016, 12, 735-764. [CrossRef]

101. Stake, R.E. The Art of Case Study Research; Sage: Newcastle, UK, 1995; pp. 1-192, ISBN 978-0803957671.

102. Yin, R. Case Study Research: Design and Methods, 6th ed.; Sage Publications: Thousand Oaks, CA, USA, 2017.

103. Mills, A.J.; Durepos, G.; Wiebe, E. Encyclopedia of Case Study Research; SAGE Publications: London, UK, 2010.

104. Edmondson, A.C.; McManus, S.E. Methodological fit in management field research. Acad. Manag. Rev. 2007, 32, 1246-1264. [CrossRef]

105. Ahrens, T.; Chapman, C.S. Doing qualitative field research in management accounting: Positioning data to contribute to theory. Account. Organ. Soc. 2006, 31, 819-841. [CrossRef]

106. Wouters, M. A developmental approach to performance measures-Results from a longitudinal case study. Eur. Manag. J. 2009, 27, 64-78. [CrossRef] 
107. Seawright, J.; Gerring, J. Case selection techniques in case study research: A menu of qualitative and quantitative options. Political Res. Q. 2008, 61, 294-308. [CrossRef]

108. Parente, R.; Feola, R.; Cucino, V.; Catolino, G. Visibility and reputation of new entrepreneurial projects from academia: The role of start-up competitions. J. Knowl. Econ. 2015, 6, 551-567. [CrossRef]

109. Bogner, A.; Menz, W. The theory-generating expert interview: Epistemological interest, forms of knowledge, interaction. In Interviewing Experts; Bogner, A., Littig, B., Menz, W., Eds.; Palgrave Macmillan: London, UK, 2009; pp. 43-80, ISBN 978-0-230-24427-6.

110. Eisenhardt, K.M.; Graebner, M.E. Theory building from cases: Opportunities and challenges. Acad. Manag. J. 2007, 50, 25-32. [CrossRef]

111. Jick, T.D. Mixing qualitative and quantitative methods: Triangulation in action. Adm. Sci. Q. 1979, 24, 602-611. [CrossRef]

(C) 2018 by the authors. Licensee MDPI, Basel, Switzerland. This article is an open access article distributed under the terms and conditions of the Creative Commons Attribution (CC BY) license (http://creativecommons.org/licenses/by/4.0/). 